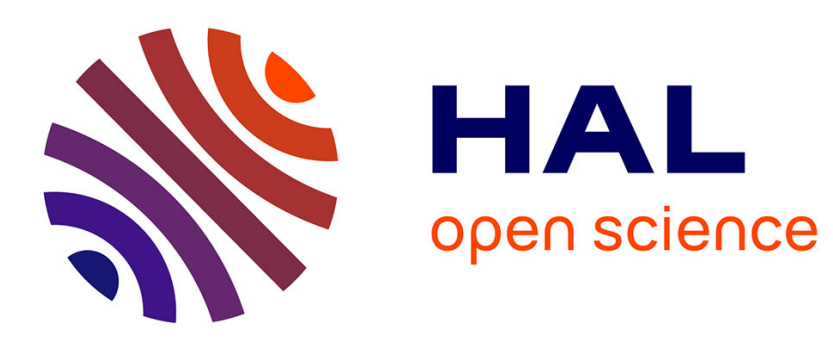

\title{
On deformation and damage micromechanisms in strong work hardening 2198 T3 aluminium alloy
}

\author{
Ante Buljac, François Hild, Lukas Helfen, Thilo F. Morgeneyer
}

\section{To cite this version:}

Ante Buljac, François Hild, Lukas Helfen, Thilo F. Morgeneyer. On deformation and damage micromechanisms in strong work hardening 2198 T3 aluminium alloy. Acta Materialia, 2018, 149, pp.29-

45. 10.1016/j.actamat.2018.01.026 . hal-01710066

\section{HAL Id: hal-01710066 \\ https://hal.science/hal-01710066}

Submitted on 27 Mar 2018

HAL is a multi-disciplinary open access archive for the deposit and dissemination of scientific research documents, whether they are published or not. The documents may come from teaching and research institutions in France or abroad, or from public or private research centers.
L'archive ouverte pluridisciplinaire HAL, est destinée au dépôt et à la diffusion de documents scientifiques de niveau recherche, publiés ou non, émanant des établissements d'enseignement et de recherche français ou étrangers, des laboratoires publics ou privés. 


\title{
On deformation and damage micromechanisms in strong work hardening 2198 T3 aluminium alloy
}

\author{
Ante Buljac ${ }^{\mathrm{a}, \mathrm{b}}$, François Hild ${ }^{\mathrm{a}}$, Lukas Helfen ${ }^{\mathrm{c}, \mathrm{d}}$, Thilo F. Morgeneyer ${ }^{\mathrm{b}, *}$ \\ ${ }^{a}$ Laboratoire de Mécanique et Technologie (LMT), ENS Paris-Saclay, CNRS, \\ Université Paris-Saclay, 61 avenue du Président Wilson, 94235 Cachan, France \\ ${ }^{b}$ MINES ParisTech, PSL Research University, Centre des Matériaux, CNRS UMR 7633, \\ BP 87, 91003 Evry, France \\ ${ }^{c}$ ANKA/Institute for Photon Science and Synchrotron Radiation \\ Karlsruhe Institute of Technology (KIT), 76131 Karlsruhe, Germany \\ ${ }^{d}$ European Synchrotron Radiation Facility (ESRF), 38043 Grenoble, France
}

\section{Abstract}

The deformation and damage micromechanisms ahead of a notch in a large flat specimen have been assessed using in situ synchrotron laminography combined with digital volume correlation for the strain evaluation in the material bulk. Despite the enhanced work hardening of the naturally aged Al$\mathrm{Cu}-\mathrm{Li}$ alloy several slanted strained bands were found from very early loading onward in the slanted fracture region. The final slanted crack followed one of the strained bands without significant ductile damage growth. In the high stress triaxiality region, close to the notch that underwent substantial local necking, two damage micromechanisms were observed, namely, i) limited void nucleation and growth from intermetallic particles, and ii) slanted shear cracks, even starting from the specimen surface and also located in single

\footnotetext{
${ }^{*}$ Corresponding author.

Email address: thilo.morgeneyer@ensmp.fr (Thilo F. Morgeneyer)
} 
grains as shown by post mortem EBSD analyses. In the intermediate region a new deformation mechanism of flip-flopping strain bands and resulting flipflopping cracks have been revealed using "projection DIC" measurements. Keywords: Digital Volume Correlation (DVC), Flat-to-slant transition, Heterogeneous plastic flow, Laminography, Work hardening

\section{Introduction}

Tearing resistance of thin sheet material is a key design parameter for transport applications [59], as it controls weight and associated fuel and energy consumption related to thin structures. The ultimate aim of the material science and mechanics community is to optimize and design microstructures and to be able to predict their associated macroscopic failure resistance. To date, this aim is very far from being achieved. Even extrapolating from a fracture test with a given geometry and associated stress state to other stress states remains very difficult [45].

Classical ductile damage growth models $[16,41]$ are not tailored to predict failure for low stress triaxialities (i.e., $<1$ ). More recent studies have been undertaken using phenomenological approaches defining the strain to failure $\epsilon_{f}$ as a function of stress triaxiality $\eta$ and Lode parameter $\mu[40,43,2,13,58]$. Experimentally, tension-torsion test results obtained by pure experimental [17] and hybrid experimental-numerical [45] procedures reveal the monotonic dependence of the strain to failure on the stress triaxiality and the characteristic asymmetric dependence on the Lode parameter. There are 
various mechanisms that are accounted for and some which are not understood (e.g., shear ductile failure, slanted cracks and nucleation/coalescence in the context of secondary void populations).

A phenomenon that highlights the complexity of the physics of ductile fracture and its challenges is the flat to slanted crack transition where the crack starts from the notch normal to the tensile direction and then flips to $45^{\circ}$ when it propagates $[31,6,1,26,36,4]$. This phenomenon is very hard to predict and poorly understood [3]. The investigation of the origin of such behaviour has engineering relevance since it has been shown that mixedmode I/III fracture leads to reduced toughness compared to pure mode I fracture [25]. Matching both stress-strain curves and crack propagation paths is difficult to achieve numerically.

Consequently, CT-like specimens were chosen to carry out in situ tests $[35,34,38]$ to gain new insights into these mechanisms. The combined use of laminography [18, 20, 19] and global Digital Volume Correlation (DVC) [51] has enabled in situ displacement fields to be measured at the microscale. Laminography is a nondestructive imaging technique, similar to tomography. However, it allows regions of interest in flat specimens to be analyzed and a wider range of stress states to be examined compared with tomography $[30,27,32,37,42]$. Thanks to DVC, bulk displacement fields can be measured and strain fields calculated [35] based on the recordings of 3D images.

For a methodical assessment of the effect of microstructure and work- 
hardening on the strain field and flat to slanted fracture, it was decided to proceed in a systematic manner by selecting a specific family of alloys using different heat treatments, i.e., change work hardening without changing the initial grain, particle and void structures. In particular, $2139(\mathrm{Al}-\mathrm{Cu})$ and 2198 (Al-Cu-Li) aluminium alloys have been studied under naturally and artificially aged conditions, thereby changing the nano-precipitate structure and the work hardening behavior [35, 34, 53, 9, 38]. Representing the latest generation of aeronautical alloys, and understanding the underlying failure mechanisms is of great interest.

Extensive analyses on CT-like specimens made of recrystallized AA2198 T8 [34, 9] have shown that in a zone close to the notch root (i.e., $\approx 800 \mu \mathrm{m}[34]$ ), and even in its immediate vicinity [9], strained bands appeared very early in the loading history. In the slanted crack region, plane strain conditions in the crack propagation direction predicted in numerical simulations [5] have been confirmed by kinematic measurements [9]. Slanted strained bands appeared well before damage, i.e., plastic flow is very heterogeneous before any significant signs of void nucleation and growth is detected at micrometer resolutions. The origin and observed behaviour (i.e., activation and deactivation) of strained bands at the microscale still remain unclear. The T8 heat treatment induces relatively high yield stress followed by little work hardening.

For AA2198 T8, it was shown by simulation of the sample geometry and von Mises plasticity or a Gurson-type model that the predicted strain fields 
were very different from the measurements, i.e., no slanted strained bands were present in the computations. This result indicated that plasticity was not described accurately by these models in the case studied.

Low work hardening materials are believed to be prone to flow localization [49]. Following this reasoning, enhanced work hardening materials should be more resistant to flow localization. However, this was not the case for another aluminium alloy (i.e., AA2139 T3). Numerous slanted strain bands were observed. Compared to AA2198 T8, their activity was substantially more intermittent [38].

The strain partitioning between the regions within and outside the slanted bands were found to be of the order of 2. Even though there was no clear definition, this behaviour may not be considered as classical localization where all strains concentrate in the localized band. Slanted strained bands, i.e., heterogeneous strains, that cannot be easily predicted by standard plasticity models, were found. Via 2D plane strain simulations have shown that a soft zone that is $10 \%$ weaker than the surrounding material leads to a strain partitioning with a factor of 2 [38]. The question now is what leads to this substantial softening in the material?

Further, damage nucleation and growth set in very late during the loading history in all these studies. Since these two alloys were different, the strain fields for AA2139 with T8 treatment and AA2198 under T3 condition remain unknown.

In this work, results obtained for a CT-like specimen made of 2198 T3 
aluminium alloy are presented. The T3 heat-treatment resulted in a microstructure responsible for high work hardening behaviour [12] as hardening precipitates were missing in this heat treated state.

The paper is structured as follows. The material properties of AA2198 T3 are first introduced. The experimental setup and the laminography imaging technique are outlined next. The basic principles of DVC incorporating strain uncertainty assessments are presented. The results are then discussed. The strain fields in the slant region $\approx 1 \mathrm{~mm}$ from the notch root are presented first. Damage growth and final fracture are then shown for all ROIs. A strain field analysis is then performed for the regions closer to the notch root. Qualitative 3D observations, but also damage quantification lead to the identification of two different damage micromechanisms. They are further assessed by post mortem SEM and EBSD microstructure analyses that are correlated with the phenomena observed from laminography and DVC results.

\section{Experimental Procedure}

\subsection{Material}

The CT-like specimen used in the present experiment is made of 2198 T3 aluminium alloy in its recrystallized state, solution heat-treated, stretched by 2-4 \%, and naturally aged to obtain the T351 (i.e., so-called T3) condition. It is produced by Constellium $C$-Tec and represents the latest generation of aluminum-copper-lithium alloys. The composition of the $\mathrm{Al}-\mathrm{Cu}-\mathrm{Li}$ alloy is shown in Table 1. Compared with the first two generations of Al-Li alloys, 
AA2198 has higher copper and lower lithium contents. This composition results in increased strength and toughness of the material which is widely used in the transportation (e.g., aeronautical) industry.

Table 1: Chemical composition limits of AA2198 in weight percent (wt. \%) and atomic

\begin{tabular}{cccccccccc}
\multicolumn{10}{l}{ percent (at. \%) [11] } \\
\hline Element & $\mathrm{Cu}$ & $\mathrm{Li}$ & $\mathrm{Zn}$ & $\mathrm{Mn}$ & $\mathrm{Mg}$ & $\mathrm{Zr}$ & $\mathrm{Si}$ & $\mathrm{Ag}$ & $\mathrm{Fe}$ \\
\hline wt. \% & $2.9-3.5$ & $0.8-1.1$ & $\leq 0.35$ & $\leq 0.5$ & $0.25-0.8$ & $0.04-0.18$ & $\leq 0.08$ & $0.1-0.5$ & $\leq 0.01$ \\
at. \% & $1.23-1.48$ & $3.11-4.26$ & $\leq 0.14$ & $\leq 0.25$ & $0.25-0.88$ & $0.01-0.05$ & $\leq 0.08$ & $0.02-0.06$ & $\leq 0.05$ \\
\hline
\end{tabular}

Microscopic observations showed that there were no significant differences in the grain structure between the T3 and T8 conditions [11]. The grain size measured by using a mean linear intercept method was equal to $200-300 \mu \mathrm{m}$ along the rolling direction (L) and also in the transverse direction (T) [11]. This has been determined to be equal to $10-15 \mu \mathrm{m}$ in the short transverse direction (S) for the recrystallized sheet by EBSD. Hence, typical pancakeshaped grains in L-T sections were found. In the experiment reported here the loading was applied in the T-direction and the L-direction corresponded to that of crack propagation.

Neither $T_{1}$ nor $\Theta^{\prime}$ hardening precipitates were found in the T3 condition. Most of the dispersoids were $\mathrm{Al}_{20} \mathrm{Cu}_{2} \mathrm{Mn}_{3}$ or $\mathrm{Al}_{3} \mathrm{Zr}$ components. The average dispersoid diameter size was $45 \mathrm{~nm}$ with a volume fraction of 1.2$1.8 \%$. Transmission Electron Microscopy (TEM) also revealed no presence of precipitate decoration of the observed grain and sub-grain boundaries nor a precipitate free zone for the T3 condition [11]. 
Intermetallic particles composed of iron and silicon (white) were elongated and aligned along the rolling direction [11]. However, low intermetallic content $(\approx 0.3-0.4$ vol. $\%)$ combined with hardly any initial porosity (i.e., $<0.03$ vol. \%) made the material challenging for DVC recording as the laminography image contrast was not very pronounced [35], see Figure 2(b).

The true stress-strain curve and a power-law fit are given in Figure 1 for a strain rate of $10^{-3} \mathrm{~s}^{-1}$ and loading in the $\mathrm{T}$ direction. The gauge section of the sample was $6 \mathrm{~mm}$ wide, $2 \mathrm{~mm}$ thick and $32 \mathrm{~mm}$ long. The fit has been performed using a classical power hardening law

$$
\sigma_{\text {true }}=K \epsilon_{\text {true }}^{n}
$$

with $K=685 \mathrm{MPa}$, and $n=0.21$. This result shows the enhanced work hardening behaviour of the $\mathrm{T} 3$ condition [12] in contrast to the $\mathrm{T} 8$ condition that only yielded a strain hardening exponent of $n=0.08$. The enhanced work hardening of the T3 heat treated material occurred from about 0.04 to 0.135 strain, which covered most of the strain range. 


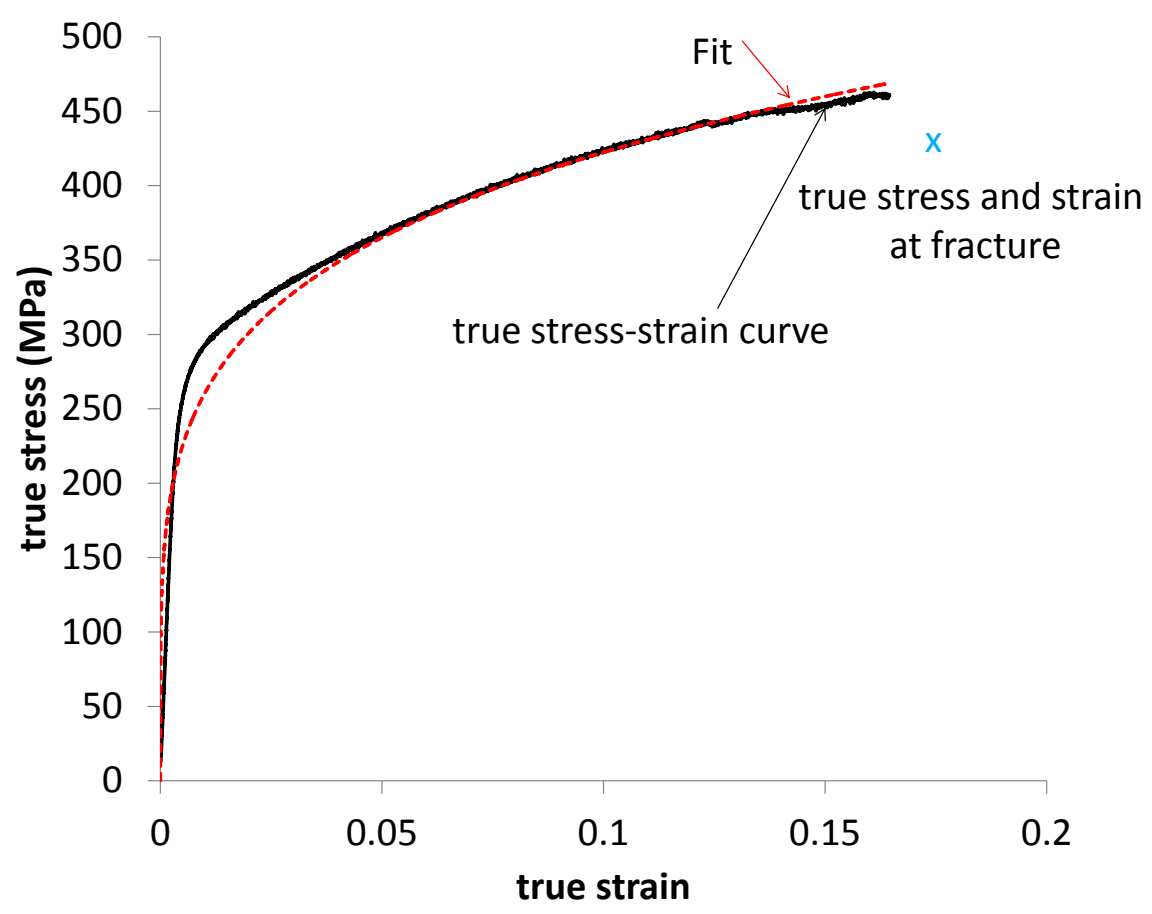

Figure 1: True stress/strain curve of AA2198 T3 and fitting curve with power hardening law

\subsection{Laminography}

Synchrotron radiation computed laminography is a nondestructive technique to image regions of interest in flat and laterally extended 3D objects $[21,33,10,47]$. This geometry is of particular interest in the field of mechanics of materials since sheet-like samples allow for a wide range of the engineering relevant boundary conditions. Laminography is related to the specimen inclination with respect to the beam direction with an angle $\theta<90^{\circ}$ (Figure 2(a)); while tomography, which is a special case of laminography, is limited to the $90^{\circ}$ angle during the scanning procedure and requires 
stick-like samples.

(a)

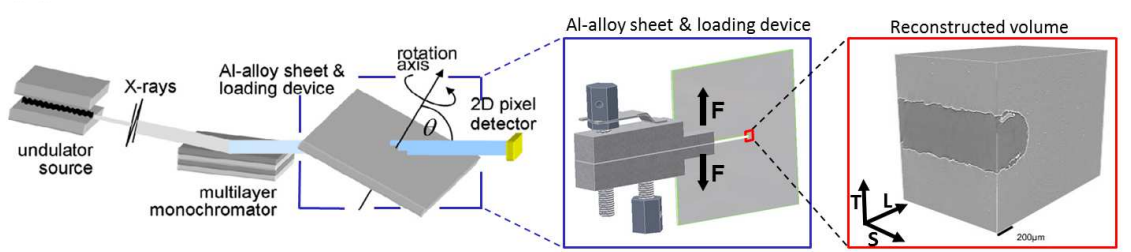

(b)
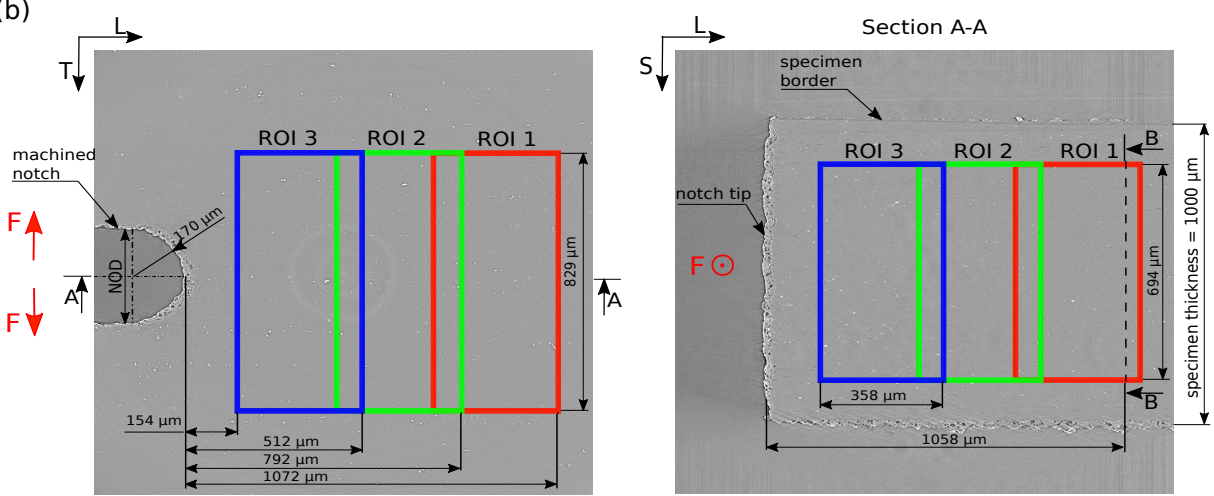

Figure 2: (a) Schematic view of the laminography setup with the loading device, CT-like sample and the scanned region (red zone). (b) 2D sections of laminography data indicating the positions of the Regions of the Interest (ROIs) examined in this work

The CT-like specimen studied in this work had the following dimensions: $60 \times 70 \times 1 \mathrm{~mm}$. It contained a machined notch $0.17 \mathrm{~mm}$ in radius produced by electrical discharge machining (Figure 2(b)). A specially designed loading device was used with a stepwise loading procedure (Figure 2(a)). The loading device incorporated an aluminium alloy frame (not shown in Figure 2(a)) to prevent out-of-plane motions of the specimen [36, 35]. After applying each loading step, the object was scanned whilst being rotated about the laminograph axis. Using the collected radiographs, 3D volumes were reconstructed 
by using a filtered back-projection algorithm [39]. In the reconstructed slices an isotropic voxel size of $0.7 \mu \mathrm{m}$ was obtained. The 3D images used in this work were obtained at beamline ID19 of the European Synchrotron Radiation Facility (Grenoble, France) with a $25-\mathrm{keV}$ monochromatic beam, using 1,500 projections and $\theta \approx 65^{\circ}$. After scanning in the undeformed state $(0), 12$ additional scans were acquired during the stepwise loading procedure, where the last two scans corresponded to the final crack opening and propagation.

\subsection{Digital Volume Correlation}

The reconstructed volume has been represented by a discrete scalar function of spatial coordinate $\boldsymbol{x}$ of (in the present case 8-bit deep) grey levels determined by the microstructure absorption of X-rays. The basic principle of DVC consists of the determination of the displacement field $\boldsymbol{u}$ for two consecutive scans in the reference, $f$, and deformed, $g$, configurations

$$
f(\boldsymbol{x})=g[\boldsymbol{x}+\boldsymbol{u}(\boldsymbol{x})]
$$

However, due to acquisition noise, reconstruction artifacts [29, 57] and the correlation procedure itself [28], ideal grey level conservation (Equation (2)) was not satisfied in real cases. Consequently, the solution consisted of minimizing the grey level residual

$$
\rho(\boldsymbol{x})=f(\boldsymbol{x})-g[\boldsymbol{x}+\boldsymbol{u}(\boldsymbol{x})]
$$

by considering its Euclidean norm (L2-norm [24]) with respect to the kine-

matic unknowns. Since a global approach was used here [51], $C_{0}$ continuity 
over the whole Region of Interest (ROI) has been applied to the solution, and the global residual which needs to be minimized becomes

$$
\Phi_{c}^{2}=\sum_{R O I} \rho^{2}(\boldsymbol{x})
$$

The displacement field was parameterized by using a kinematic basis consisting of fields $\Psi_{p}(\boldsymbol{x})$ and amplitudes $u_{p}$

$$
\boldsymbol{u}(\boldsymbol{x})=\sum_{p} u_{p} \boldsymbol{\Psi}_{p}(\boldsymbol{x})
$$

At this level of generality, a variety of fields could be chosen [23]. Finite element shape functions were particularly attractive because of the link they provided between the measured displacement fields and numerical models [46, 7]. Thus, a DVC formulation based on 8-noded cubes (i.e., C8 finite elements) with trilinear shape functions was chosen [51] in this work. Mean gradients of the displacement field over each C8 element were used to calculate the Hencky strain tensor [22].

The reconstructed volume had a size of $2040 \times 2040 \times 2040$ voxels. The correlation procedure using the whole volume size would have been computationally too demanding. Therefore an extracted Region of Interest (ROI) was used for DVC analyses. Three different ROIs with dimensions $1184 \times 512 \times 992$ voxels were selected. The first was located approximately $1 \mathrm{~mm}$ from the notch root (as in previous works [34, 38]), whilst the other two were closer (Figure 2(b)). A mutual overlap of 112 voxels (i.e., $78.4 \mu \mathrm{m}$ ) was chosen to check the consistency of the results. As could be expected, 
most of the DVC recordings obtained for ROI 1 could not be obtained for ROI 2 and ROI 3 since complex displacement fields developed in the immediate vicinity of the notch root. Although few of them converged, the results obtained for these ROIs were valuable since they were located in the zone of the flat-to-slant transition.

Before discussing any result, an uncertainty assessment will be presented. It consisted of analyzing two consecutive scans of the unloaded sample with ("rbm") and without ("bis") applying rigid body motion between the two acquisitions. In the "rbm" case the sample was moved by $u_{T}=-15$ voxels, $u_{L}=586$ voxels and $u_{S}=3$ voxels. For ROI 3, the "rbm" case was missing since applying a rigid body motion moved this part of the sample out of the scanned region. The uncertainty values have been evaluated by the standard deviation of the measured displacement and calculated strain fields [8]. Figure 3 shows the strain resolution levels for the three inspected ROIs. It must be emphasized that these uncertainty levels incorporate cumulated effects of laminography and DVC. The element size used in this work was $\ell=32$ voxels (i.e., C8 element length for all three directions), which yielded a standard effective (in von Mises' sense) strain resolution of $0.3 \%$ (Figure 3). This strain level represents the limit below which strain measurements were not trustworthy. No significant effect of the ROI location was observed. Conversely, the application of rigid body motions slightly increased the standard strain resolution. 


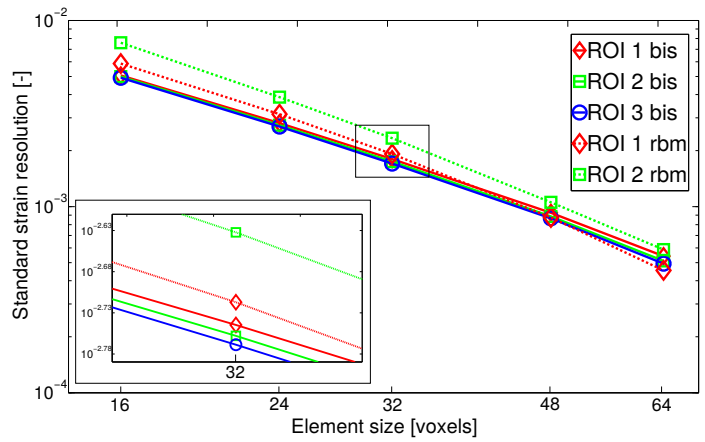

Figure 3: Standard von Mises strain resolution as a function of the element size used in the DVC procedure

A stepwise loading procedure resulted in the Notch Opening Displacement (NOD) history shown in Figure 4. Measurements were taken approximately $200 \mu \mathrm{m}$ from the initial notch root and in the notch as shown in Figure 2(b). NOD data for the two ultimate loading steps (State (11) and (12)) are missing since the crack had already propagated through the ligament area (Figure 4). The measurement uncertainty of the NOD was $+-5 \mu \mathrm{m}$. 


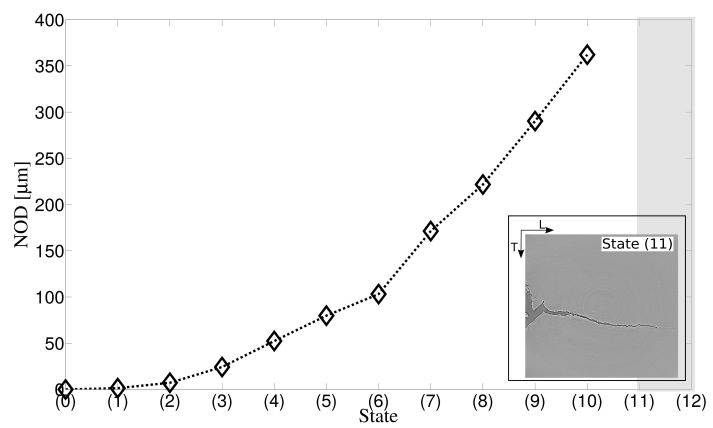

Figure 4: Notch Opening Displacement (NOD) for the step-wise loading procedure followed in this work; mid-thickness section showing the final crack propagated through the specimen ligament area for loading step (0)-(11)

\subsection{Projection Digital Image Correlation}

To obtain further strain fields in the region close to the notch root for all load increments and to link them to the final crack path, a new "projection DIC" procedure has been proposed. The idea and assumption are the following. The region farther away from the notch has been shown to be in plane strain conditions in the crack propagation direction [9]. As a consequence, the contrast provided over a certain thickness in the propagation direction can be projected onto one single plane and used to perform in-plane correlation (i.e., classical 2D DIC [23]). The result of the procedure in which contrasts (the maximum grey level values) from $50 \mu \mathrm{m}$ thick slices are projected onto one plane (to become a $2 \mathrm{D}$ image) is shown in Figure 5(b). It is observed that the contrast is enhanced compared to a simple $2 \mathrm{D}$ section (Figure 5(a)). This procedure allows faster correlations to be obtained than 
for a 3D volume in DVC and it also helps convergence.

With these "pseudo" 2D images, regularized T3-DIC was performed [55] with an unstructured triangular mesh with 3-noded elements of size 32 pixels and regularization length of 256 pixels. This configuration resulted in a standard strain uncertainty of $0.029 \%$ ("bis" case) and $0.03 \%$ ("rbm" case) for the reported normal strains in the loading direction.

A comparison in terms of normal strain in the loading direction is shown for DVC (Figure 5(c) left) and "projection DIC" (Figure 5(c) right). The strain fields were very similar. This result validates this new "projection DIC" procedure. 


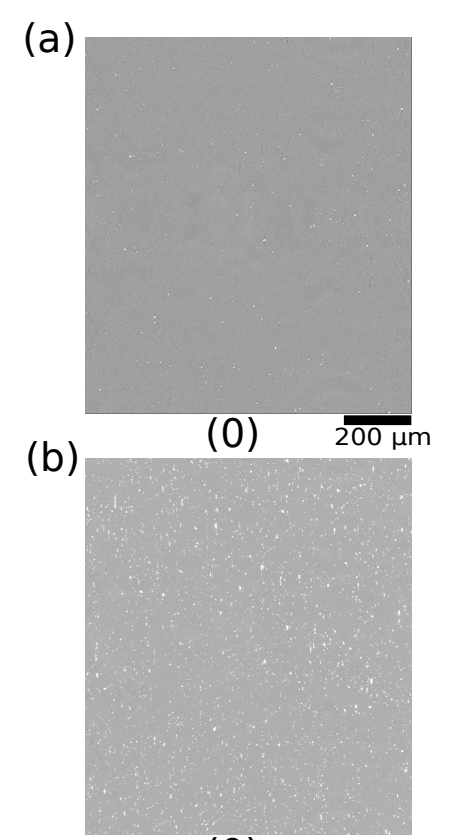

(0)

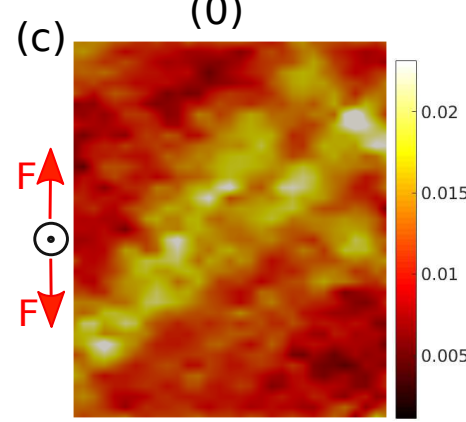

DVC (0)-(3)

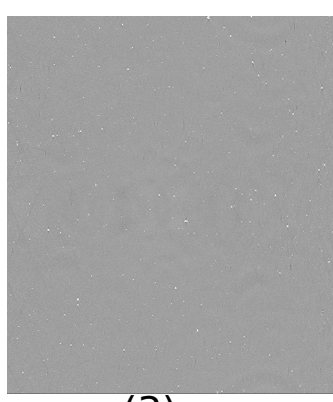

(3)

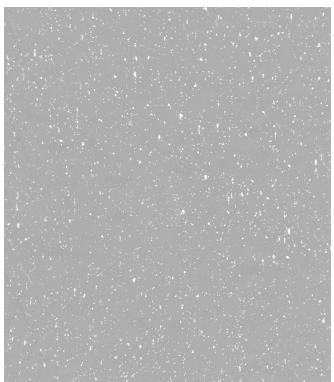

(3)

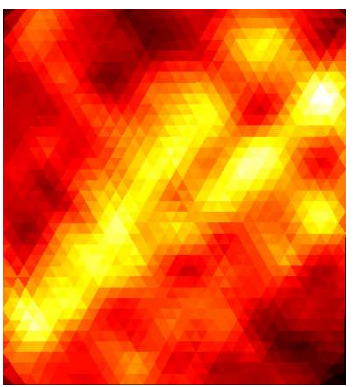

$\operatorname{DIC}(0)-(3)$

$\odot$ crack propagation direction

Figure 5: Comparison of DVC and "projection DIC" results. (a) 2D sections of reconstructed laminography data for load steps (0) and (3). (b) Projected 2D sections of reconstructed laminography data (the maximum values were taken over a thickness of $50 \mu \mathrm{m})$. (c) Comparison of normal strain fields obtained by DVC (left) and "projection DIC" (right) on projected 3D data 


\section{Results}

\subsection{Effective strain fields in slant region (ROI 1)}

Direct calculations refer to the results obtained by correlating the undeformed volume (State (0)) and the corresponding deformed configuration (State $(n)$ ), whilst incremental calculations stand for correlation between any reference volume (State $(n))$ and subsequent (State $(n+1))$ configuration. As mentioned before, ROI 1 , which was located $\approx 1 \mathrm{~mm}$ from the initial notch root (Figure 2(b)), occupied the region that would contain a fully slanted crack. For ROI 1, direct calculations up to the loading step (7) converged successfully, whilst the last converged incremental loading step calculation was between States (7) and (8). The final crack in this (slanted) region appeared at State (11), see Figure 4.

Section B-B of ROI 1 (Figure 2(b)) was followed through the loading history (Figure 6)for a meaningful observation of the material behaviour, . The section was positioned $\approx 1058 \mu \mathrm{m}$ from the initial notch root normal to the crack propagation direction (L). Figure 6 shows von Mises effective strains for section B-B for different loading steps. The colour bar scale has been adjusted to the range of values for the corresponding section. Figure 6(a) corresponds to the results for direct calculations whilst Figure 6(b) consists of the results for incremental loading steps. Since incremental calculations update the calculation frame (i.e., nodal positions), special care has been taken to ensure that the same section was selected throughout the loading

process. This was done by tracking several specific microstructural features. 
Strain heterogeneities appeared very early on in the loading process, both in the case of incremental and direct calculations. The maximum level of strains in the band for the first direct calculation was $1.4 \%$, except for the band that was the most active, other bands are also observed as part of the strain pattern. They were inclined at about $45^{\circ}$ and crossed each other at right angles. Activation and deactivation of these background bands resulted in plastic strain accumulation in all these zones. The final slanted crack paths followed the most pronounced band already detected at loading step (0)-(3) as will be shown below. 
(a) Section B-B

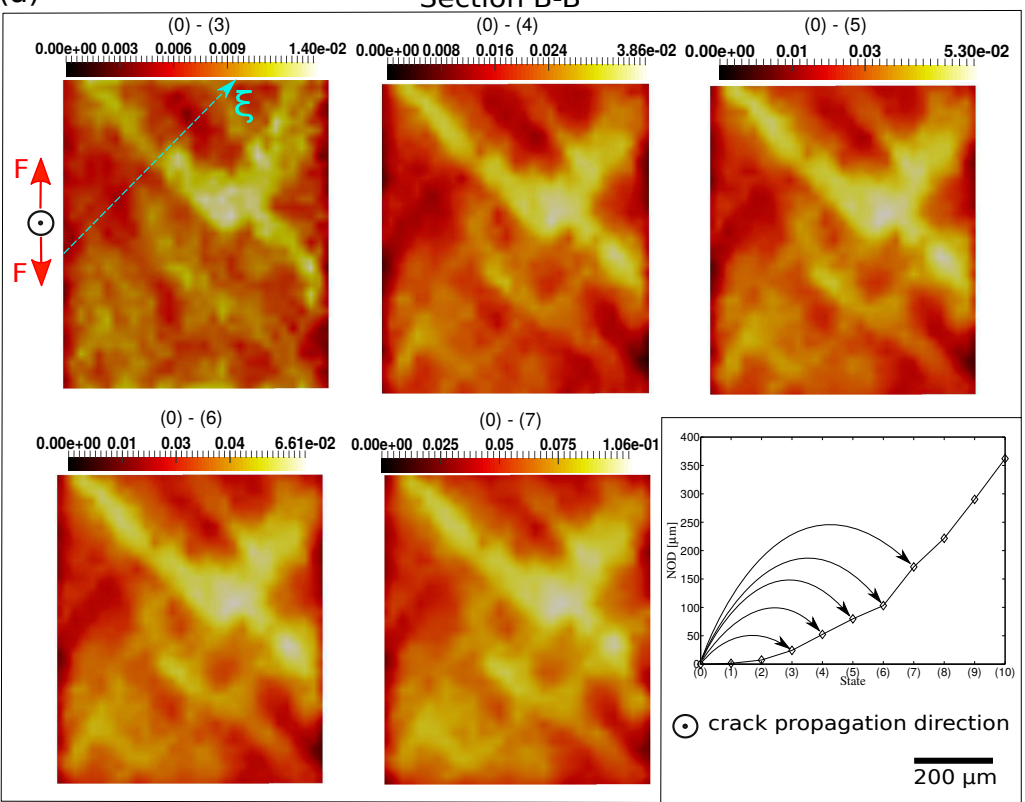

(b)

Section B-B

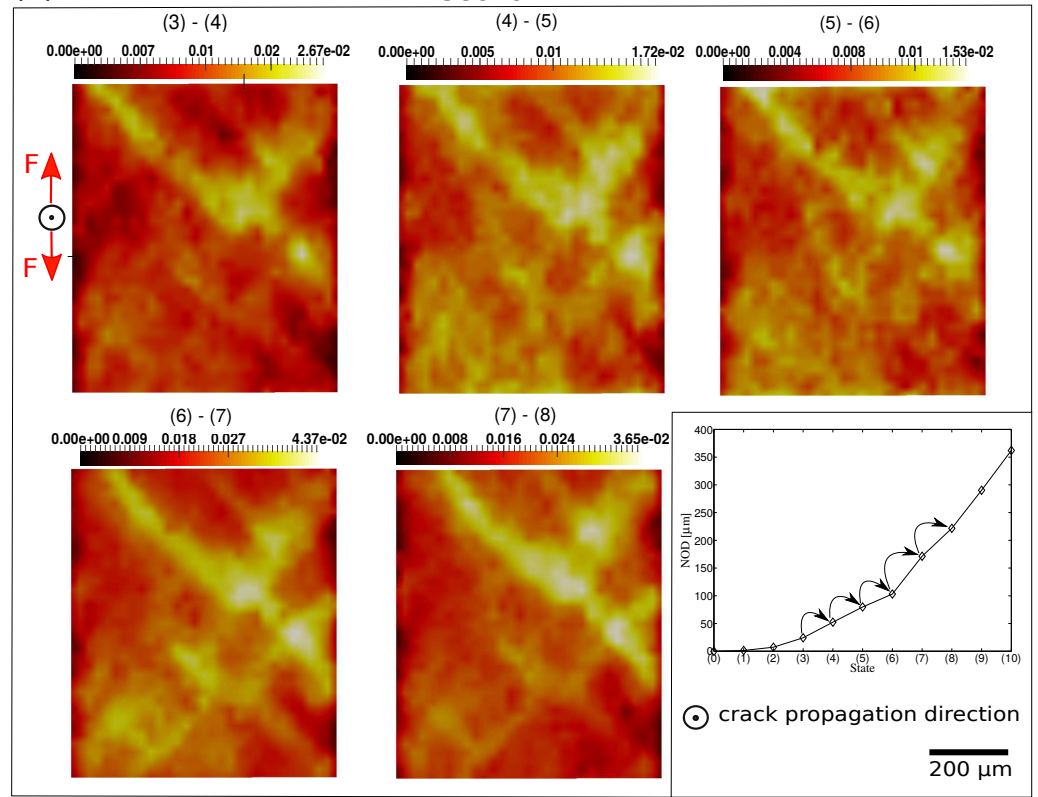

Figure 6: Digital volume correlation results. Section normal to the crack propagation direction (i.e., section B-B, Figure 2(b)) showing von Mises effective strain fields for direct (a) and incremental (b) calculations 
Figure 7 shows the effective strain profiles plotted along the axis $\xi$ depicted in Figure 6(a) for direct calculations. These profiles allow a quantification of the strained bands. The curves have been characterized by a pronounced peak marking the strained band position. The strain levels in the bands, e.g., for loading step (0)-(3), were at least one order of magnitude greater than the strain uncertainty. Hence, the measured strain heterogeneities represented a significant mechanical signal rather than noise. The band width can be seen to be $\approx 150-200 \mu \mathrm{m}$, i.e., two (or more) times greater than the reported grain size in the short (S) transverse direction. The remaining part of ROI 1 did not behave as an elastic body. The bulk part was less active than that for the bands, but strains there steadily increased throughout the loading history, which resulted in the generation of high strains after several loading steps. However, the strain levels in the bands were significantly higher, keeping the ratio between out-of-band and in-band strain levels within the range $0.5-0.55$ for incremental and equal to 0.5 for direct calculations over the whole loading history. Hence, despite greater hardening in AA2198 T3, these findings confirm the results obtained for AA2198 T8 [34] in the sense of the early onset of slanted strained bands keeping a constant strain ratio between in-band and out-of-band material portions of the ROI. 


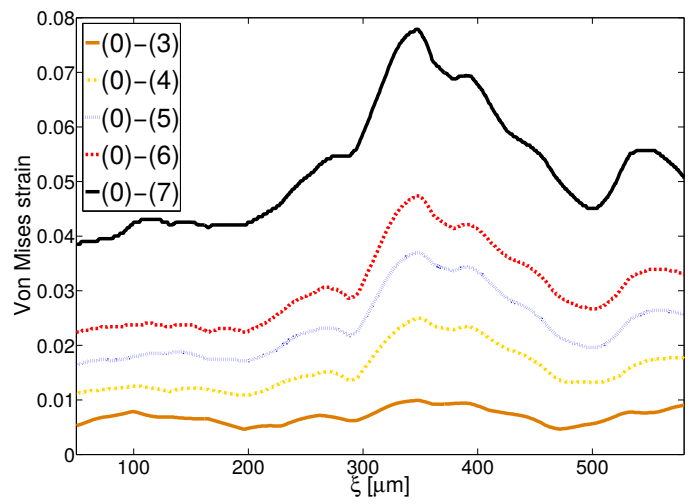

Figure 7: Von Mises effective strains along the line $\xi$ depicted in Figure 6(a) for direct digital volume correlations

\subsection{Damage and fracture evolution and quantification}

In Figure 8 microstructure states are shown for different loading steps in the mid-thickness of the sample as 2D sections of reconstructed 3D laminography data. Void growth occurred at late stages, but only in the zone close to the notch root due to high triaxiality stress states. The final crack started to propagate here toward the damage feature (visible from State (9) on) close to the notch root when it changed its direction of propagation.

For the interpretation of the damage mechanisms knowledge of the local stress state and, in particular stress triaxiality, is crucial. For a material that has a similar elastoplastic behaviour (i.e., AA2139 T3), FE calculations using a Gurson-type model have been fitted for an experiment using the same sample geometry in order to determine the stress states in different ROIs [56]. In the region close to the notch (i.e., ROI 3) stress triaxilities up to 1.2 have been found in the specimen centre. In the region where the crack was slanted 
the stress triaxiality was well below 1 over most of the deformation history. At the surface the triaxiality decreased from 0.6 to about 0.4 in both regions.

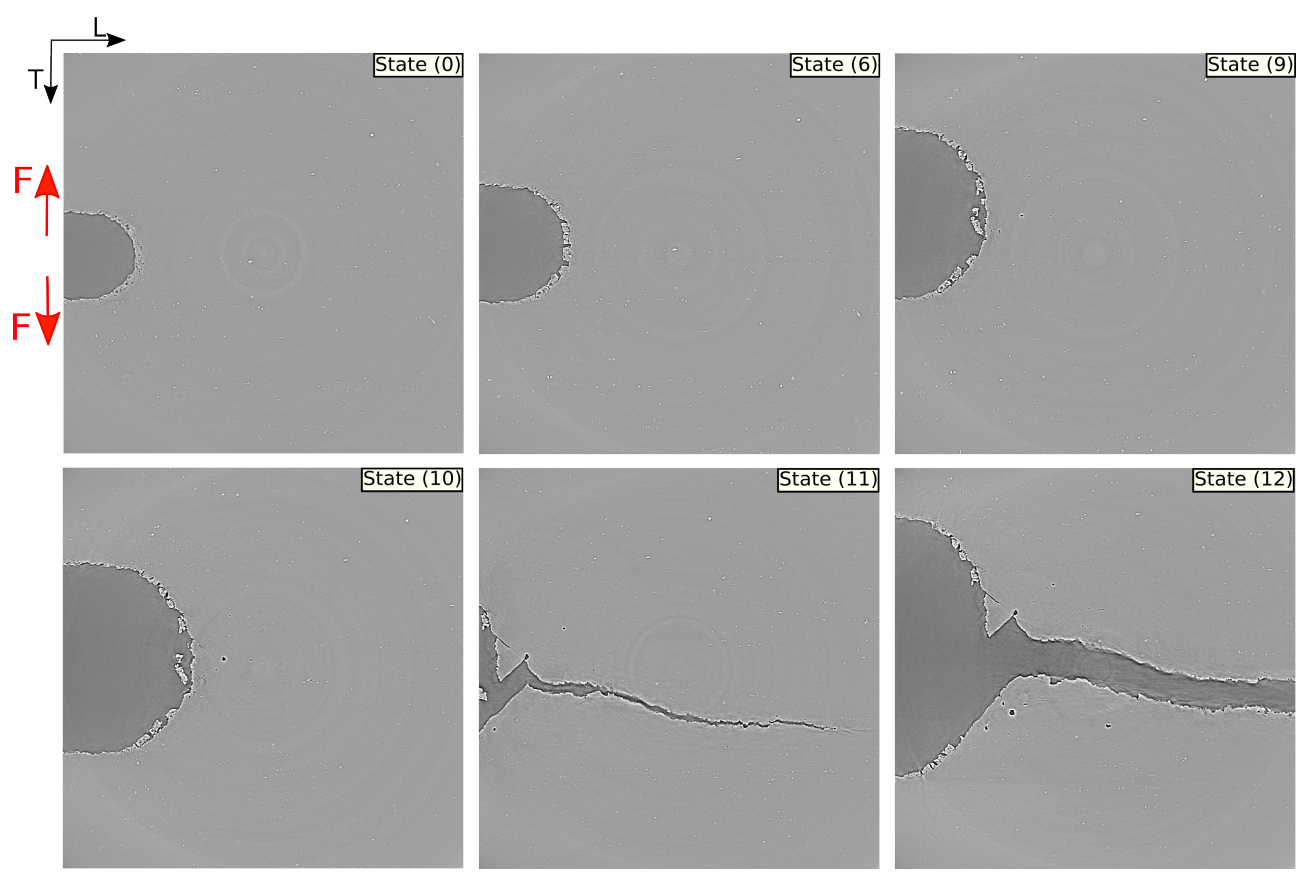

Figure 8: Mid-thickness sample section of the reconstructed volume for different loading steps indicated in every image

To obtain a statistically more relevant impression of damage in the volume, Figure 9 reveals damage growth in the three ROIs (e.g., ROIs 2 and 3) that are shown normal to the crack propagation direction. These 3D renderings show damage only, i.e., the matrix was made transparent in the $350 \mu \mathrm{m}$ thick ROIs. It is worth mentioning, as seen from Figure 2(b), that the ROIs overlapped so that some of the damage features were shared by the two neighbouring ROIs. ROI 3, in the left column of the figure, which 
is closest to the notch root, showed the highest porosity content before final crack propagation. ROI 2 experienced less void growth but still showed some damage growth before final failure. ROI 1 did not show any significant void growth before failure, which is consistent with the change in the stress state and the observed strain pattern. It is also consistent with ROI 1 being in a plane strain condition, i.e., virtually no strain in the crack propagation direction [9]. 


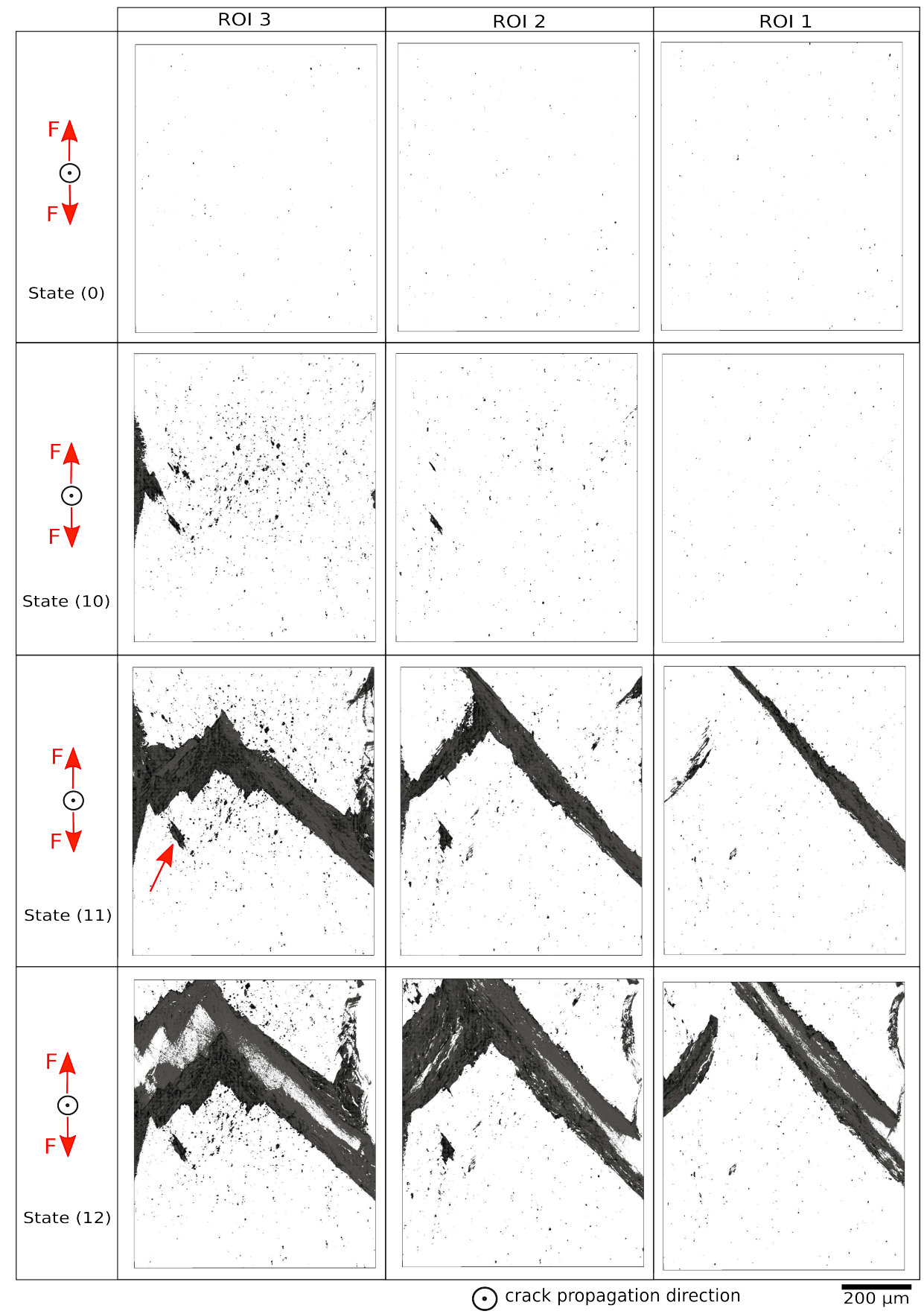

Figure 9: $3 \mathrm{D}$ visulaizations of segmented voids of ROIs 1,2 and 3 for the undeformed configuration and last three loading steps 
It has been confirmed that, due to the high stress concentrations in the immediate vicinity of the notch root, damage grew in a classical manner and decreased when moving away from the notch root. However, this is not sufficient to explain the observed shape of the final failure. Significant necking occurred close to the notch root (see Figure 9 for ROI 3 and State (10). Although damage grew in this zone, the crack started to propagate from a low stress triaxiality area close to the surface where less void growth occurred. This reveals the competition between the two micromechanisms. The first, which is plasticity driven (i.e., shear-type) and the second characterized by void growth and a softening phase prior to coalescence and final failure. The latter will be referred to as classical high stress triaxiality induced micromechanism. The flat fracture zone therefore underwent a combination of these two mechanisms.

Consequently, the void growth observed in the vicinity of the notch root was divided into two types. The first was characterized by an equiaxial growth of the voids originating from particle breakage/debonding and mostly determined by the existing stress state. The second corresponded to the elongated dark surfaces $\left(\approx 45^{\circ}\right.$ with respect to the loading direction $\left.\mathrm{T}\right)$ in Figure 9 that may represent transgranular cracks originating from shear slip systems, as will be shown below. Contrary to the slant zones, these elongated features are detected in the flat zone since they also grew due to higher hydrostatic parts of the stress tensor.

As a result of this competition, the final crack, even in the flat Region, 
behaved in a zigzagged manner [14]. There was no regular damage pattern in Figure 9 (i.e., State (10), black region on the left being the specimen surface due to necking), which explains such crack propagation. However, from the early loading steps on, zigzagged strain patterns occurred in this zone.

The volume fractions of voxels in the ROIs having grey levels below the threshold GL $=110$ are plotted in Figure 10(a). The curves correspond to an estimation of the damage variable (i.e., void fraction) inside ROIs 1, 2 and 3 (Figure 2(b)) during the loading history. For the first six loading steps there was virtually no damage growth. After loading step (0)-(6), the higher triaxiality stress state around the notch root generated higher void growth inside ROIs 2 and 3.

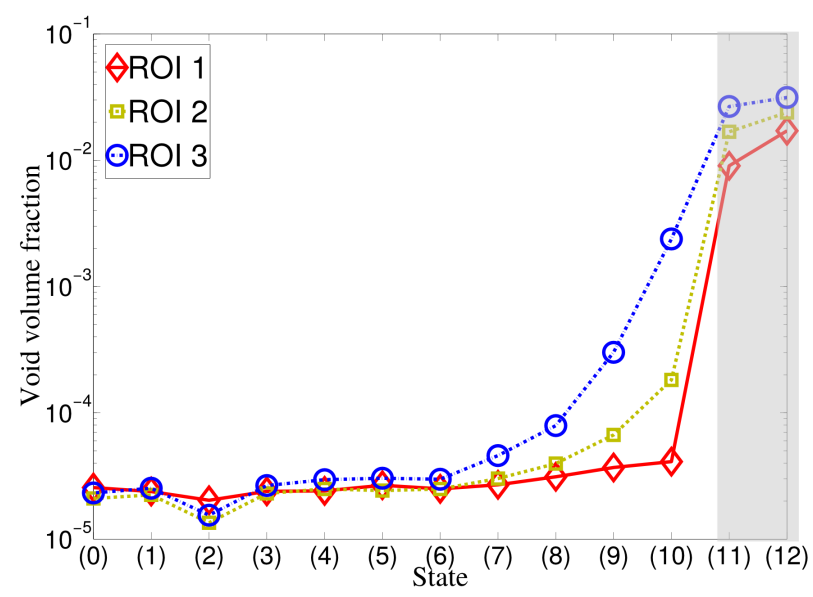

Figure 10: Void fraction development over the loading history for the three inspected ROIs (see Figure 2(b)). The shadow region denotes the final crack propagation through the ligament as shown in Figure 4

For ROI 1 there is no evidence of void volume fraction increase until final 
failure (states (11) and (12)). Hence, under the selected sub-micrometer spatial resolution (i.e., $0.7 \mu \mathrm{m}$ ) and achieved temporal resolution (number of loading steps, see Figure 4), nucleation and void growth in the slanted region were not detected until the final crack propagated (i.e., for loading step (0)-(11)). It is worth noting that heterogeneous plastic strain fields were detected at this location from loading step (0)-(3) on. Hence, the bands developed very early on in the loading history and it is very unlikely that damage softening triggered localization. Furthermore, after flow localization was initiated, void growth was still very limited up to strain levels (in the bands) of $10 \%$ or more. Further information on damage growth inside and outside the strained bands is given in Appendix A. Damage detection via correlation residuals is also shown in the appendix.

An illustration of the final fracture of the scanned sample is depicted in Figure 11 by showing its height map in conjunction with a section of an early strain field. The final crack followed the early strained band. Note that the location of the strained band did not coincide perfectly with the crack as the strain field is shown in the initial (i.e., undeformed) configuration. In Figure 11, the complete crack surface was first extracted from laminography data followed by assigning a colour to each voxel according to its distance to the L-S plane. The crack started to propagate in a "roof-top" manner without any fully flat location on the crack and then evolved to a fully slanted path at $\approx 500 \mu \mathrm{m}$ from the notch root. No clear link between the microstructure and the final crack could be found. The main crack propagated in a transgranular 
way, which was not influenced by the grain orientation and size. The strain band orientations and subsequent absence of (detectable) damage growth suggest crystallographic glide as the most likely micromechanism behind the observed failure behaviour.

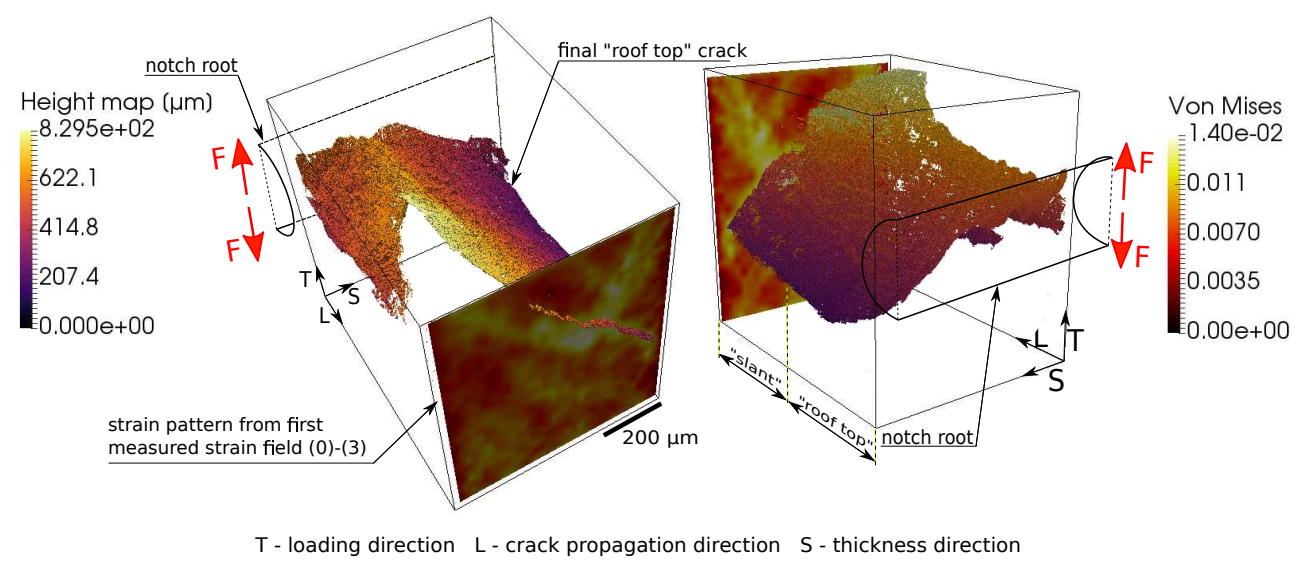

Figure 11: Final crack position in conjunction with the initial von Mises effective strain map plotted along the section normal to the crack propagation direction (L) for loading step (0)-(3). The height of the final roof-top crack is shown with the colour map. Left: view at $1 \mathrm{~mm}$ from the notch root; Right: view in the crack propagation direction

The strain to fracture has been estimated in the laminography image of the failed sample by measuring its thickness at failure compared to the initial thickness. The Hencky strain of the thickness reduction in ROI 3, close to the notch was -0.39 , whereas in ROI 1 at $1 \mathrm{~mm}$ from the notch root it was only -0.20. This observation highlights that the early strain concentrations in the slanted fracture region lead to lower average strains to fracture. This is also consistent with the difference between strain states of these two region. ROI 1 is known to be in a plane strain state with respect to the crack propagation 
direction [9], which is again confirmed here (see Figure 13).

As will be shown in future papers, post mortem observations of the fractured surface in this zone reveal mostly flat regions with small secondary voids or no voids at all.

\subsection{Strain fields closer to notch root (ROIs 2 and 3)}

Accounting for the previous results, a second analysis was performed closer to the notch root. Converged correlations exist for ROI 2 and ROI 3 just for the early loading steps. Direct calculation results for loading step (0)-(3) are available for all three ROIs. Figure 12 displays sections normal to the crack propagation direction of effective strain maps where $L$ indicates the distance from the initial notch root. Already the section closest to the notch root $(L=180 \mu \mathrm{m})$ can be seen to have contained strained bands (note the colour bar scale range). Hence, even in the immediate vicinity of the notch root, inclined strained bands crossing each other at right angles were already distinguished inside the highly concentrated zone.
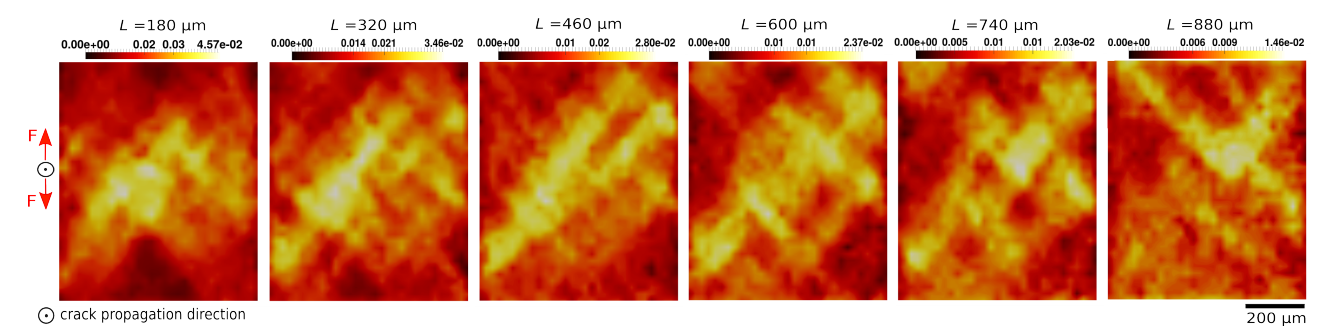

Figure 12: Sections normal to the crack propagation direction showing von Mises effective strain fields for loading step (0)-(3) for different distances from the notch root 
For section $L=460 \mu \mathrm{m}$ slanted strained bands were observed. Considering the limited damage growth for ROIs 2 and 3 at state (3), see Figure 10, it can be concluded that one of the strained bands determined the final slanted crack path. Interestingly,farther away from the notch root $(L=740 \mu \mathrm{m})$ other secondary bands were (re)activated. Finally, in section $L=880 \mu \mathrm{m}$ one of the secondary bands became even more pronounced whilst at the same time previous primary slanted bands remained active to a lesser extent. The spatial distribution was even more complex than the temporal one. In particular, the activation of secondary bands normal to the primary one was an important phenomenon for understanding the strain activity.

The through-thickness $(\mathrm{S})$ sections for all three merged ROIs containing the effective (a) and normal strains (b-d) for loading step (0)-(3) are shown in Figure 13. The reported normal strain components have been calculated as nominal strains. The ROI boundaries are marked due to higher measurement uncertainties at the edges. However, the overall consistency of the results was satisfactory for different calculations (i.e., different ROIs). The colour bar scales have been adjusted to the data range of the corresponding field, except for the effective and normal strains in the loading direction $\epsilon_{T T}$ where maximum values have been limited to 0.2 . This level has been chosen so as to increase the band visibility since considerable variations occurred between the strain levels close to and farther away from the notch root. For each case, three through-thickness sections are displayed where $d$ denotes the distance between the observed sections and the ROI midplane thickness, which is 
roughly the specimen midplane thickness .

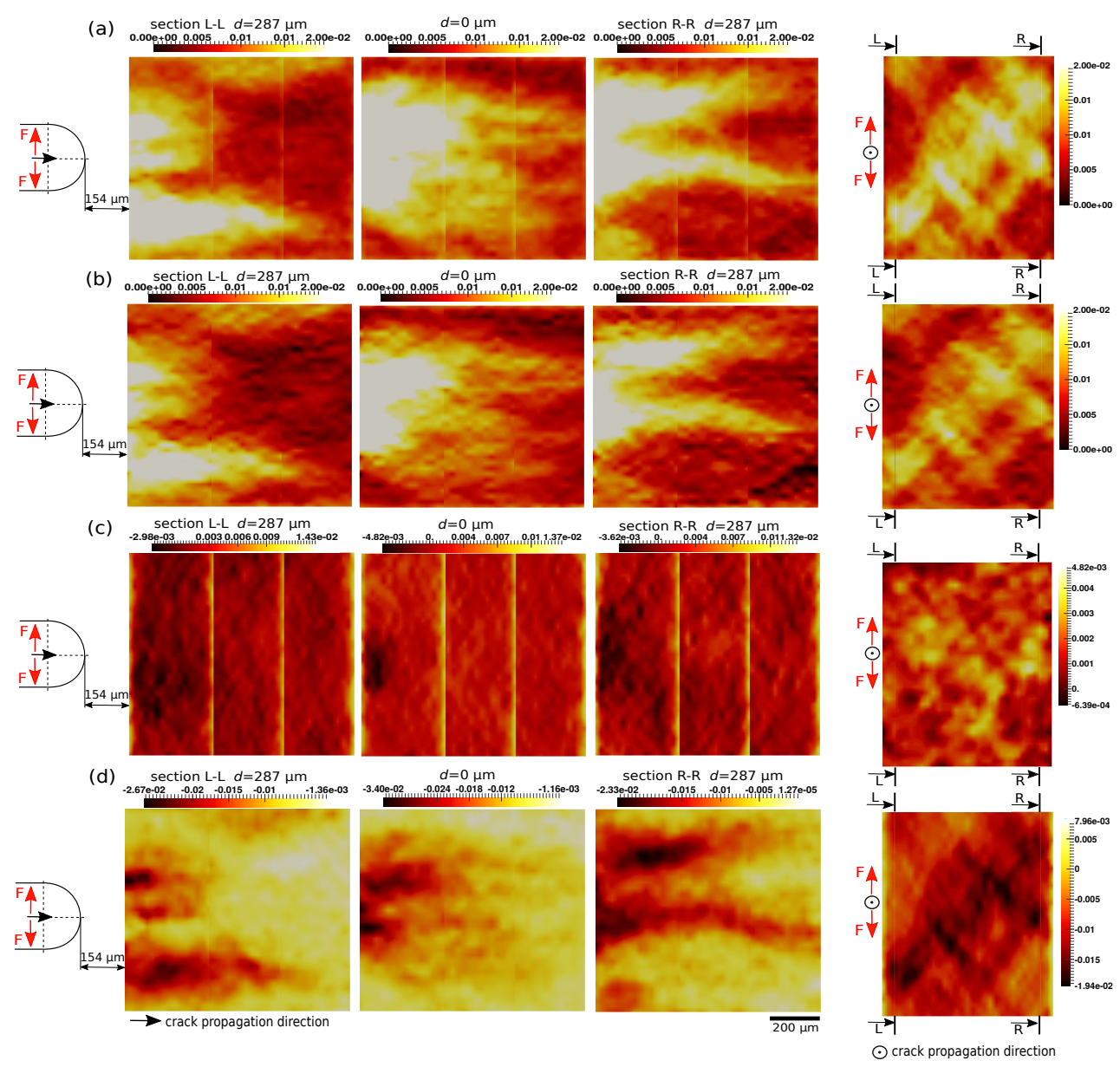

Figure 13: Sheet plane sections of merged ROIs 1, 2 and 3, where $d$ denotes the distance from the ROI mid-thickness plane. Positions of the L-L and R-R sections are depicted on the section normal to the crack propagation direction (right column). (a) Von Mises effective strains $\epsilon_{e q}$, (b) normal strains in the loading direction $\epsilon_{T T}$, (c) normal strains in the crack propagation direction $\epsilon_{L L}$, (d) normal strains in the through thickness direction $\epsilon_{S S}$. Normal strain components are defined as nominal strains.

Figure 13 confirms that normal strains $\epsilon_{T T}$ and $\epsilon_{S S}$ were responsible for 
the observed heterogeneous effective strain fields. Normal strain levels in the crack propagation direction $\epsilon_{L L}$ (Figure 13(c)) were close to zero except in the necking zone with negative strains in the immediate vicinity of the notch root. Plane strain conditions were observed, which were consistent with earlier observations [5, 9]. For normal strains in the through-thickness direction $\epsilon_{S S}$ (Figure 13(d)) there existed a strong dependence along the S-axis. The contraction zones with minimum strain levels corresponded to the band positions. Shear strains $\epsilon_{L S}$ (not shown) were insignificant and their distribution did not reveal any heterogeneous patterns that matched the position of the effective strain bands. One possible explanation is related to the scale used which could not properly capture the underlying shear.

\subsection{Incremental flip-flopping strain activity and final failure in the interme- diate region ( $R O I_{2}$ )}

The strain activity and roof-top cracking in the intermediate region (i.e., about $460 \mu \mathrm{m}$ from the notch root) have been assessed up to failure. DVC could only converge for the first loading steps. This was due to the complexity and levels of the strain fields but also to damage nucleation and growth. "Projection DIC" has successfully been applied (see Figure 5)so as to be able to follow the strain activity to the very end,In the early loading steps, shown in Figure 14, primary strained bands developed from the lower left to the upper right corners of the investigated region. Some "hot spots" forming a band normal to the main band were also activated. From load step (8) 
on this normal band became the most active and the former primary bands were less active. Some bands parallel the former main band in the upper left corner suddenly became active and, surprisingly, this led to the final roof-top crack that can be seen in the last overlaid image. The corresponding surface strain activity measurements are reported in Appendix A. 


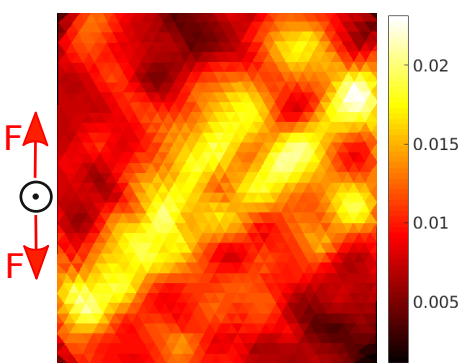

$(0)-(3)$

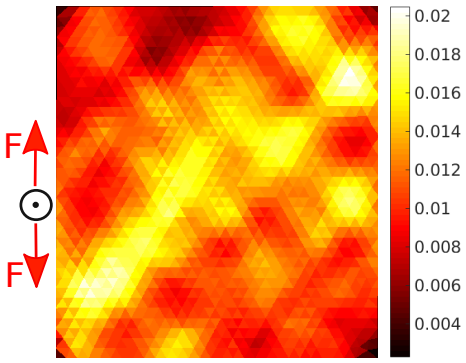

(5)-(6)

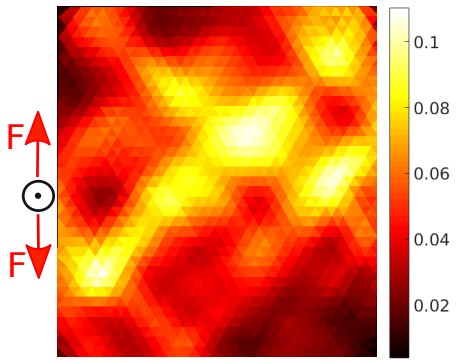

(8)-(9)

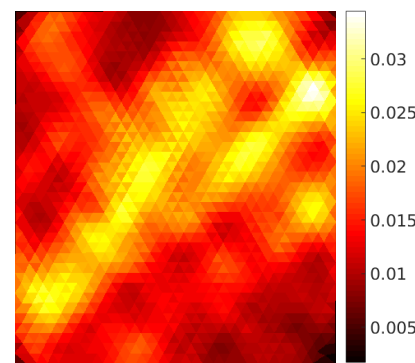

(3)-(4)

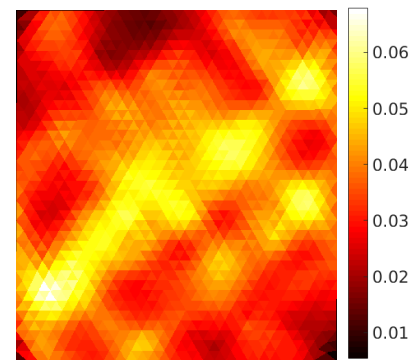

(6)-(7)

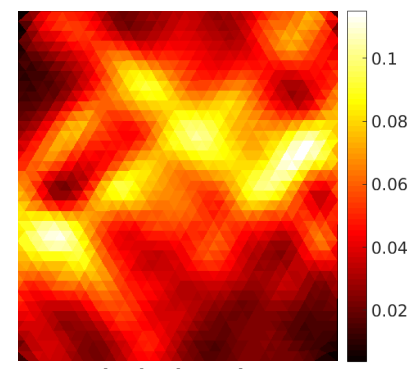

(9)-(10)

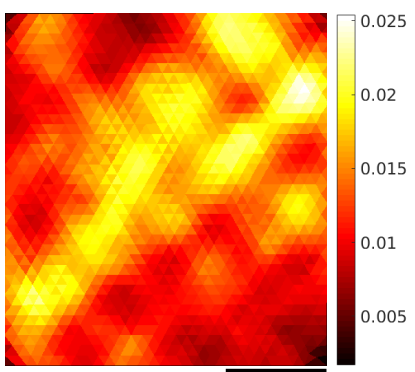

(4)-(5) $200 \mu \mathrm{m}$

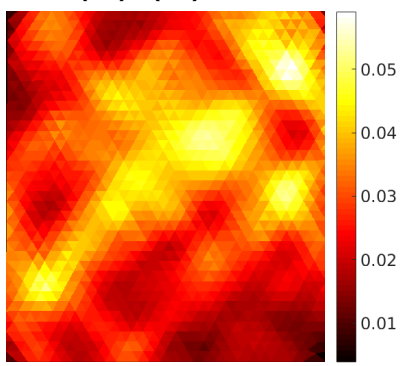

$(7)-(8)$

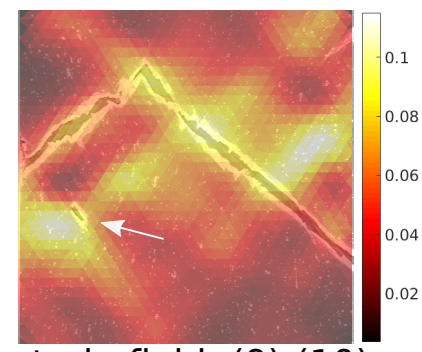

strain field: (9)-(10)

microstructure: (11)

Figure 14: Incremental normal strain maps (in the loading direction) in ROI 2 (i.e., $460 \mu \mathrm{m}$ from the notch root) for different load steps and overlay of the last possible incremental strain field with the final crack path

A new flip-flopping deformation mechanism has been found, which can explain the flip-flopping behaviour of the crack. This behaviour could be linked to the hardening behaviour of this naturally aged material. Hardening within bands may make deformation in another band easier. The Portevin-Le 
Chatelier effect might also be at play here. The presence of several crossing strained bands was clearly the origin of the zigzagging crack near the notch root. This phenomenon has been found in different engineering materials [52, 38]. There is one damage feature indicated by an arrow that was always present on the main strained band. The nature of this feature will be further assessed in the following sections using EBSD analyses.

\subsection{Post mortem observations}

The damage feature indicated in Figure9 by a red arrow was examined by Electron BackScattered Diffraction (EBSD) analyses (Figure 15). Although it inevitably induced certain void growth and edge rounding, electrolytic polishing (EP) needed to be used in order to obtain satisfactory diffraction figures. The damage feature dimensions were measured prior to (Figure 15(a)) and after EP for which a $\approx 25 \%$ change in length occurred. From Figure 15(b) it can be observed that the inspected feature exhibited transgranular failure. The dimensions of the damage feature measured (from laminography data) at its initiation stage (i.e., State (10), Figure 14) were equal to $\approx 140 \mu \mathrm{m}, \approx 35 \mu \mathrm{m}$ and $\approx 40 \mu \mathrm{m}$ for $\mathrm{L}, \mathrm{S}$ and $\mathrm{T}$ directions, respectively. From Figure 15, the S component of the grain size measured at the hole position was equal to $\approx 40 \mu \mathrm{m}$, thereby confirming that the damage feature originated from a transgranular crystal crack event. 
(a)

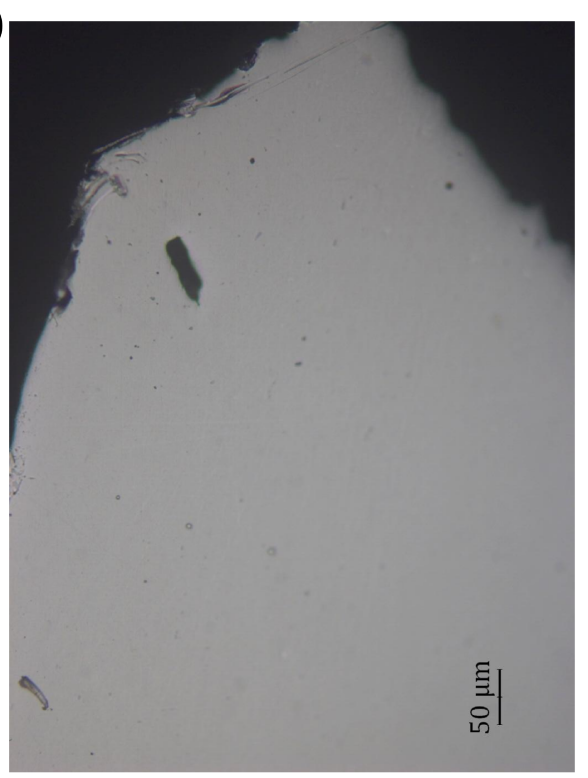

$\odot$ crack propagation direction (b)
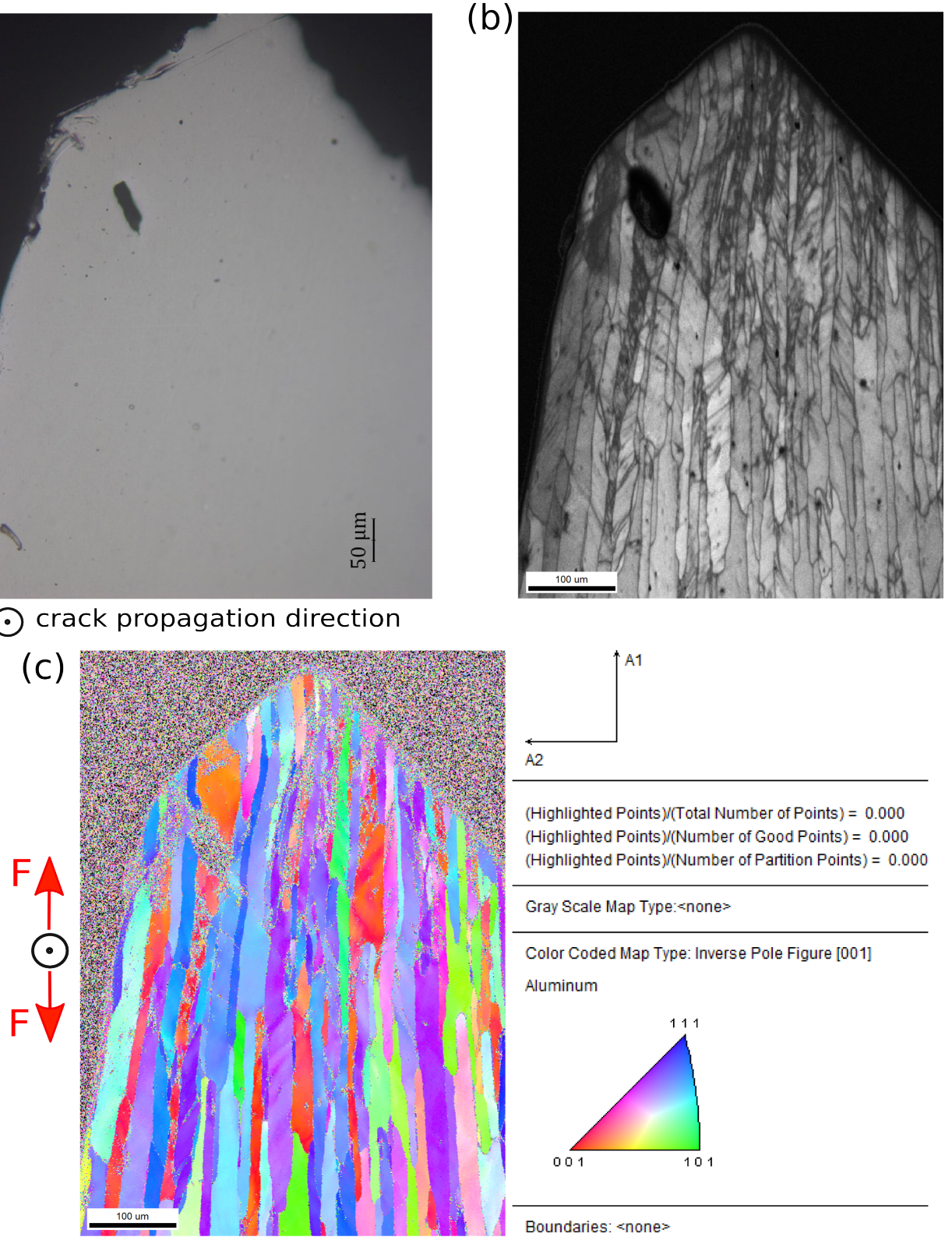

Figure 15: Electron backscattered diffraction taken at one side of the broken CT-like specimen on the section normal to the crack propagation direction. (a) View before electropolishing. (b) Grain texture revealing the transgranular nature of the inspected damage feature (denoted with red arrow in Figure 9 at State (11) and white arrow in Figure 14). (c) Inverse pole figure showing the grain orientations where the damaged grain with its 37

001 orientation was sandwiched between 111 oriented grains 
The presence of intensely strained bands forming an " $\mathrm{X}$ " shape around the observed damage feature should be noted. They extended over multiple grains as previously reported. Although initiated in several of them, the crack opened significantly only in a particular one. The inverse pole figure (Figure 16(c)) reveals that the damaged grain had a different orientation from the surrounding grains. This difference may have induced slip incompatibilities between the grains and it may also have induced induced stress concentrations, which explain to some extent the reported single grain breakage.

Scanning electron micrographs are shown in Figure 16. In Figure 16(a) a "roof-top" type of the failure path can be recognized. The crack started to propagate in a "roof-top" manner, but since the slanted side close to the depicted subset a was pinned, it continued to propagate in a fully slanted manner. Figure 16(a) also contains other subset positions that are shown magnified in Figure 16(b). 
(a)

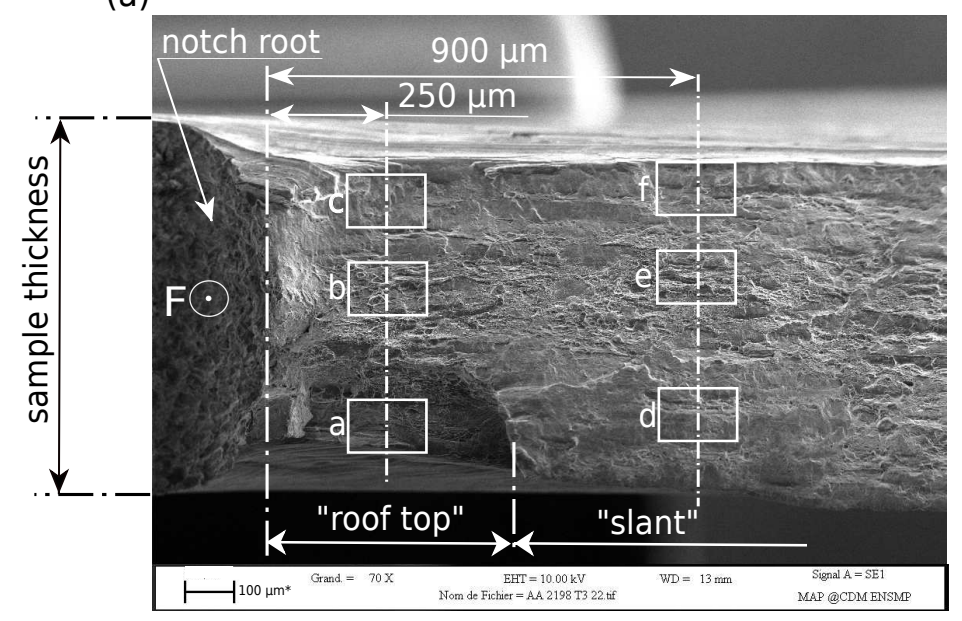

(b)

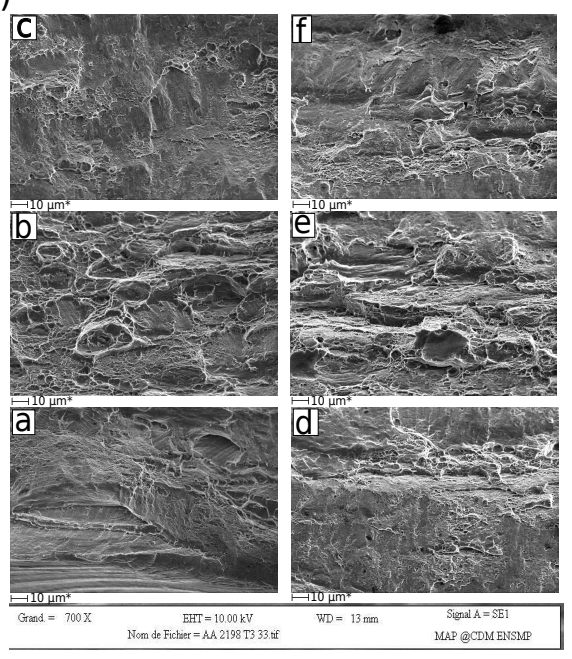

(c)
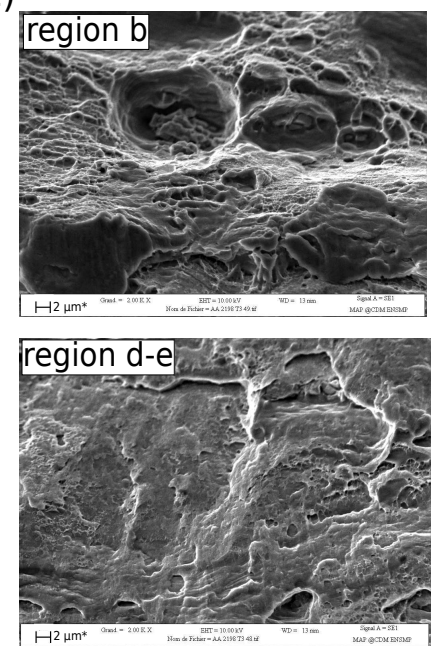

Figure 16: Scanning electron micrographs taken at one side of the broken CT-like specimen. (a) Magnification level $\times 70$, triangular zone at the notch root followed by slant surfaces. (b) Maginification level $\times 700$, magnified subsets a-f depicted in (a). (c) Maginification level $\times 2000$, zoomed details from subset $\mathrm{b}$ and from the zone between subsets e and $d$.

Dimpled zones corresponding to higher triaxiality levels were found 
around the mid-thickness plane (subsets $\mathrm{b}$ and $\mathrm{e}$ ), $\approx 250 \mu \mathrm{m}$ and $\approx 900 \mu \mathrm{m}$ from the notch root. The slanted areas were detected close to the sample surface where the stress triaxiality levels decreased. Finally, two locations, in subset $\mathrm{b}$ (region $\mathrm{b}$ ) and between subsets $\mathrm{d}$ and $\mathrm{e}$ (region $\mathrm{d}-\mathrm{e}$ ) are depicted and shown enlarged in Figure 16(c). Region b reveals primary and secondary void growth features but also incorporates final shear surface alignment (i.e., classical equiaxed void growth and shear-type micromechanism). On the other side, region e shows a fully slanted spot without any signs of void growth or coalescence (i.e., shear-type micromechanism).

The SEM results support the proposed two types of damage growth mechanisms, especially the micrographs under higher magnification (regions $\mathrm{b}$ and d-e). For subset e higher stress triaxialities caused some void growth at very late stages of loading when the final crack was already propagating, although no void growth was detected during loading according to in situ the laminography scans. This result highlights the importance of in situ experiments since post mortem observations integrate all the events during the underlying experiment, without the possibility of positioning the events in time and knowing the weighted contribution of each of them to the observed damage mechanisms.

\section{Discussion}

Despite the strong work hardening of AA2198 T3, the deformation pattern in the future slanted fracture region of a notched sample was concen- 
trated in slanted bands in the thickness direction that preceded the final crack. Even though there was no clear definition, the strained band did not represent classical strain localization in the sense that all plastic strains would occur within the band but rather a heterogeneous strain field with a strain partitioning between the slanted band and the surrounding material. The ratio of the strain within and outside the band was of the order of 2 . A similar level was found for low work hardening AA2198 T8 [34], and for AA2139 T3 [38], which does not contain Li.

Using von Mises Plasticity or Gurson-type model for simulations of the experiment, the slanted strained bands could not be reproduced [34]. As the slanted fracture region is known to be in a state of plane strain [9], 2D plane strain simulations were carried out accounting for soft zones [38]. A zone that is $10 \%$ softer than the bulk material leads to similar strain partitioning as found in the experiment (i.e., a ratio of the order of 2).

The question is: what is the origin of this softening mechanism other than damage softening and how to explain such regular shapes of the soft zones? Taupin et al. [54] modelled the 2D grain structure of a fibered 2198 alloy to predict the strain partitioning (note that in the present work the material was in a recrystallized state with consequently larger grains in the $\mathrm{S}$ direction and substantially less texture). One of the configurations in their work accounting for 19 grains in the thickness direction and was the closest to that in the present study. In the ROI investigated in this work there were $\approx 50$ grains in the thickness (see Figure 15). The strain bands in the result 
of Taupin et al. did not cross the full section but were only partial and depended on the local grain orientation. The strained bands found in this work crossed the entire section and seem unaffected by local grain orientations. With 50 grains in the thickness this should define a fully polycrystalline condition. Further, the strained bands found by the authors were inclined with respect to the loading direction but the angle was substantially higher than the one found here. Moreover, the strain partitioning was greater compared to reported DVC measurements. The difference between a crystal plasticity configuration, where highly strained bands in single grains and their neighbours can be found, and the mesoscopic polycrystalline configuration found in this work is the length scale. Despite the fact that there were 50 grains in the ROI, the main strained bands crossed the entire section of the sample. This was even more pronounced for AA2139 T3 where slanted bands were found but grains were even smaller [38]. To summarize, looking for crystallographic effects is certainly interesting but the fully polycrystalline situation found here needs to be accounted for.

Portevin - Le Chatelier (PLC) effect could be one of the possible origins of softening and slanted band development (in particular their intermittent activity [48]). The flip-flopping of the bands would also be consistent with behaviour that is found in the intermediate region. These findings would then be in contrast with the recent work of Ovri et al. [44] where for naturally aged AA2198, negative strain rate sensitivity and associated instabilities were not reported. However, the loading conditions, sample geometries and stress 
states (i.e., microtensile and nanoindentation tests) during those experiments differed significantly from the present work. In works by Rousselier et al. [50] the experiments using CT like samples on AA2198 T8 were simulated combining a PLC model with fracture models and the early slanted bands were reproduced successfully, thereby implying that PLC is a possible origin for the slanted band development. In the simulations a Rousselier model was used to account for void growth at crack initiation and a Coulomb model at the transgranular slip scale to account for fracture at lower levels of stress triaxiality and negligible void growth. Both, the early slanted strain bands and the flat to slanted crack transition could be reproduced successfully. The only feature of the experimental findings that was not so similar to PLC is that the slanted bands remained stable in space. This could be due to the natural effect of the notch concentrating the bands in the space.

Felter and Nielsen [15] have attempted to model slanted cracks and in particular the flip-flopping of a crack in a plate. They used a low work hardening material (i.e., $n=0.05$ ) and turned the grips experimentally and numerically, which yielded in a successful flip-flopping of the crack. However, the strain fields ahead of the notch were not shown and it would be interesting to see if they look similar to the present findings. In the present work an antibuckling device was used. Consequently, the out-of-plane rotations, which can indeed have a strong influence on the fracture process, were very limited by the anti-buckling frame. The anti-buckling device may actually have favoured symmetrical cracking, i.e., a roof-top crack, rather than a slanted 
crack, which makes the process asymmetric. The present finding on slanted strained bands and their flip-flopping activity may actually be at the origin of the flip-flopping that Felter and Nielsen also described [15].

Possible origins of the intrinsic material deformation mechanism in slanted bands of intermittent activity could be crystallographic effects in conjunction with PLC effects. These mechanisms should be investigated further.

\section{Conclusions}

It has been shown here, using 3D imaging and kinematic measurement techniques in the material bulk, that enhanced work hardening does not significantly change the results reported on AA2198 T8 (i.e., same material but with low work hardening [34]) concerning the early development of slanted strained bands ahead of a notch in a large flat specimen. In the present case, the slanted strained bands were observed even earlier in the loading history since more loading steps were performed during the experiment. In the slanted fracture regions, strained bands appeared very early on, before any signs of the onset of damage. Void nucleation and growth have been quantified. It was found to be very low in the slanted fracture region. SEM fractography revealed that in this region hardly any dimples, not even on a very small scale, were present.

In the high stress triaxiality $(>1)$ region close to the notch root, two separate damage micromechanisms have been identified, namely, i) shear- 
type damage and ii) more classical high stress triaxiality induced damage. Even in the "flat" fracture zone the shear-type micromechanism prevailed, which produced the zigzagged final crack pattern close to the notch root. Both EBSD and SEM analyses correlated the results obtained in this work and were consistent with such assumptions.

In the intermediate region, at about $460 \mu \mathrm{m}$ from the notch root, a new deformation mechanism of flip-flopping slant strained bands was revealed. It led to a flip-flopping roof-top crack. This observation has been obtained using a new "projection DIC" technique. Under the assumption of plane strain condition in the propagation direction, which is satisfied, image contrast is projected onto a single slice of material for different loading steps. With these 2D projections classical 2D-DIC could be performed. This analysis allowed extremely complex strain fields to be measured even during the onset of damage.

To complete the present findings and previous studies, AA2139 with T8 treatment should also be investigated. Other classes of aluminium alloys (e.g., 6XXX, 5XXX or 7XXX series alloys) could also be analyzed to confirm or not the presence of slanted strained bands and the generality of the present findings.

\section{Acknowledgements}

The financial support of the Fédération Francilienne de Mécanique and Agence Nationale de la Recherche (ANR-14-CE07-0034-02 grant for COMIN- 
SIDE project) is gratefully acknowledged. Constellium C-Tec supplied the studied alloy. The authors also acknowledge the European Synchrotron Radiation Facility for provision of beamtime at beamline ID19 (experiments MI-1149 and MA-1631). Fabrice Gaslain from Mines ParisTech is thanked for help with EBSD analysis and Sicong Ren for performing the tensile test.

[1] A. Asserin-Lebert, J. Besson, and A.F. Gourgues. Fracture of 6056 aluminum sheet materials: effect of specimen thickness and hardening behavior on strain localization and toughness. Mat. Sci. Eng., A395(12):186-194, 2005.

[2] Y. Bai and T. Wierzbicki. Application of extended mohr-coulomb criterion to ductile fracture. Int. J. Fract., 161(1):1-20, 2010.

[3] J. Besson. Continuum models of ductile fracture: A review. Int. J. Damage Mech., 19:3-52, 2010.

[4] J. Besson, C.N. McCowan, and E.S. Drexler. Modeling flat to slant fracture transition using the computational cell methodology. Eng. Fract. Mech., 104:80-95, 2013.

[5] F. Bron and J. Besson. Simulation of the ductile tearing for two grades of 2024 aluminum alloy thin sheets. Eng. Fract. Mech., 73(11):1531-1552, 2006.

[6] F Bron, J Besson, and A Pineau. Ductile rupture in thin sheets of 
two grades of 2024 aluminum alloy. Mat. Sci. Eng., A380(1-2):356-364, 2004.

[7] A. Buljac, M. Shakoor, J. Neggers, M. Bernacki, P.-O. Bouchard, T.F. Morgeneyer, and F. Hild. Numerical Validation Framework for Micromechanical Simulations based on Synchrotron 3D Imaging. Comput. Mech., $59(3): 419-441,2017$.

[8] A. Buljac, T. Taillandier-Thomas, L. Helfen, T.F. Morgeneyer, and F. Hild. Evaluation of measurement uncertainties of digital volume correlation applied to laminography data. The Journal of Strain Analysis for Engineering Design, in Press :DOI: 10.1177/0309324717748097, 2018.

[9] A. Buljac, T. Taillandier-Thomas, T.F. Morgeneyer, L. Helfen, S. Roux, and F. Hild. Slant strained band development during flat to slant crack transition in AA 2198 T8 sheet: in situ 3D measurements. Int. J. Fract., 200(1):49-62, 2016.

[10] D. J. Bull, L. Helfen, I. Sinclair, S. M. Spearing, and T. Baumbach. A Synthesis of Multi-Scale 3D X-ray Tomographic Inspection Techniques for Assessing Carbon Fibre Composite Impact Damage. Compos. Sci. Technol., 75:55-61, 2013.

[11] J. Chen. Ductile tearing of AA2198 aluminium-lithium sheets for aero- 
nautic application. Phd thesis, 2011. Ecole Nationale Supérieure des Mines de Paris.

[12] A. Deschamps, B. Decreus, F. De Geuser, T. Dorin, and M. Weyland. The influence of precipitation on plastic deformation of $\mathrm{Al}-\mathrm{Cu}-\mathrm{Li}$ alloys. ACTA MATERIALIA, 61(11):4010-4021, 2013.

[13] M. Dunand and D. Mohr. On the predictive capabilities of the shear modified Gurson and the modified Mohr Coulomb fracture models over a wide range of stress triaxialities and Lode angles. J. Mech. Phys. Solids, 59(7):1374-1394, 2011.

[14] S.A. El-Naaman and K.L. Nielsen. Observations on mode I ductile tearing in sheet metals. Eur. J. Mech. A/Solids, 42:54-62, 2013.

[15] C.L. Felter and K.L. Nielsen. Assisted crack tip flipping under mode I thin sheet tearing. European Journal of Mechanics - A/Solids, 64:58 $68,2017$.

[16] A.L. Gurson. Continuum Theory of Ductile Rupture by Void Nucleation and Growth: Part I - Yield Criterion and Flow Rules for Porous Ductile Media. ASME J. Eng. Mat. Techn., 99:2-15, 1977.

[17] S.S. Haltom, S. Kyriakides, and K. Ravi-Chandar. Ductile failure under combined shear and tension. Int. J. Solids Struct., 50(10):1507-1522, 2013. 
[18] L. Helfen, T. Baumbach, P. Mikulík, D. Kiel, P. Pernot, P. Cloetens, and J. Baruchel. High-resolution three-dimensional imaging of flat objects by synchrotron-radiation computed laminography. Appl. Phys. Lett., 86(7):071915, 2005.

[19] L. Helfen, T.F. Morgeneyer, F. Xu, M.N. Mavrogordato, I. Sinclair, B. Schillinger, and T. Baumbach. Synchrotron and neutron laminography for three-dimensional imaging of devices and flat material specimens. Int. J. Mat. Res., 2012(2):170-173, 2012.

[20] L. Helfen, A. Myagotin, P. Mikulík, P. Pernot, A. Voropaev, M. Elyyan, M. Di Michiel, J. Baruchel, and T. Baumbach. On the implementation of computed laminography using synchrotron radiation. Rev. Sci. Instrum., 82(063702), 2011.

[21] L. Helfen, A. Myagotin, P. Pernot, M. DiMichiel, P. Mikulík, A. Berthold, and T. Baumbach. Investigation of hybrid pixel detector arrays by synchrotron-radiation imaging. Nucl. Inst. Meth. Phys. Res. B, 563:163-166, 2006.

[22] F. Hild, E. Maire, S. Roux, and J.F. Witz. Three dimensional analysis of a compression test on stone wool. Acta Mat., 57:3310-3320, 2009.

[23] F. Hild and S. Roux. Digital image correlation. In P. Rastogi and E. Hack, editors, Optical Methods for Solid Mechanics. A Full-Field Approach, pages 183-228, Weinheim (Germany), 2012. Wiley-VCH. 
[24] R. A. Horn and C. R. Johnson. Norms for Vectors and Matrices. Cambridge, England: Cambridge University Press, 2007.

[25] S.V. Kamat and J.P. Hirth. Mixed mode fracture toughness of engineering materials. J. Eng. Mater. Technol., 117(4):391-394, 1995.

[26] W. Lan, X. Deng, M. A. Sutton, and C.S. Chen. Study of slant fracture in ductile materials. Int. J. Fract., 141:469-496, 2006.

[27] C. Landron, E. Maire, J. Adrien, H. Suhonen, P. Cloetens, and O. Bouaziz. Non-destructive 3-D reconstruction of the martensitic phase in a dual-phase steel using synchrotron holotomography. Scripta Mat., 66(12):1077-1080, 2012.

[28] H. Leclerc, J.N. Périé, S. Roux, and F. Hild. Voxel-scale digital volume correlation. Exp. Mech., 51(4):479-490, 2011.

[29] N. Limodin, J. Réthoré, J. Adrien, J.Y. Buffière, F. Hild, and S. Roux. Analysis and artifact correction for volume correlation measurements using tomographic images from a laboratory x-ray source. Exp. Mech., 51(6):959-970, 2011.

[30] J. Lorthios, F. Nguyen, A.-F. Gourgues, T.F. Morgeneyer, and P. Cugy. Damage observation in a high-manganese austenitic TWIP steel by synchrotron radiation computed tomography. Scripta Mat., 63(12):1220$1223,2010$. 
[31] E. Mahgoub, X. Deng, and M.A. Sutton. Three dimensional stress and deformation fields around flat and slant cracks under remote mode I loading conditions. Eng. Fract. Mech., 70:2527-2542, 2003.

[32] E. Maire and P. J. Withers. Quantitative X-ray tomography. Int. Mat. Rev., 59(1):1-43, 2014.

[33] V. Maurel, L. Helfen, F. N'Guyen, A. Köster, M. Di Michiel, T. Baumbach, and T.F. Morgeneyer. Three-dimensional investigation of thermal barrier coatings by synchrotron-radiation computed laminography. Scripta Mat., 66:471-474, 2012.

[34] T. Morgeneyer, T. Taillandier-Thomas, L. Helfen, T. Baumbach, I. Sinclair, S. Roux, and F. Hild. In situ 3D observation of early strain localisation during failure of thin $\mathrm{Al}$ alloy (2198) sheet. Acta Mat., 69:78-91, 2014.

[35] T.F. Morgeneyer, L. Helfen, H. Mubarak, and F. Hild. 3D Digital Volume Correlation of Synchrotron Radiation Laminography images of ductile crack initiation: An initial feasibility study. Exp. Mech., 53(4):543$556,2013$.

[36] T.F. Morgeneyer, L. Helfen, I. Sinclair, H. Proudhon, F. Xu, and T. Baumbach. Ductile crack initiation and propagation assessed via in situ synchrotron radiation computed laminography. Scripta Mat., 65:1010-1013, 2011. 
[37] T.F. Morgeneyer, H. Proudhon, P. Cloetens, W. Ludwig, Q. Roirand, L. Laiarinandrasana, and E. Maire. Nanovoid morphology and distribution in deformed HDPE studied by magnified synchrotron radiation holotomography. Polymer, 55(25):6439-6443, 2014.

[38] T.F. Morgeneyer, T. Taillandier-Thomas, A. Buljac, L. Helfen, and F. Hild. On strain and damage interactions during tearing: 3D in situ measurements and simulations for a ductile alloy (AA2139-T3). J. Mech. Phys. Solids, 96:550-571, 2016.

[39] A. Myagotin, A. Voropaev, L. Helfen, D. Hänschke, and T. Baumbach. Efficient Volume Reconstruction for Parallel-Beam Computed Laminography by Filtered Backprojection on Multi-Core Clusters. IEEE Trans. Image Process., 22(12):5348-5361, 2013.

[40] K. Nahshon and J.W. Hutchinson. Modification of the gurson model for shear failure. Eur. J. Mech. A/Solids, 27:1-17, 2008.

[41] A. Needleman and V. Tvergaard. An analysis of ductile rupture in notched bars. J. Mech. Phys. Solids, 32(6):461-490, 1984.

[42] Michael J. Nemcko, Hua Qiao, Peidong Wu, and David S. Wilkinson. Effects of void fraction on void growth and linkage in commercially pure magnesium. Acta Mat., 113:68-80, 2016.

[43] Tvergaard V. Nielsen, K.M. Ductile shear failure or plug failure of 
spot welds modelled by modified Gurson model. Eng. Fract. Mech., 77(7):1031-1047, 2010.

[44] H. Ovri and E.T. Lilleodden. New insights into plastic instability in precipitation strengthened Al-Li alloys. Acta Mat., 89:88-97, 2015.

[45] J. Papasidero, V. Doquet, and D. Mohr. Determination of the Effect of Stress State on the Onset of Ductile Fracture Through Tension-Torsion Experiments. Exp. Mech., 54(2):137-151, 2014.

[46] J. Rannou, N. Limodin, J. Réthoré, A. Gravouil, W. Ludwig, M.C. Baïetto, J.Y. Buffière, A. Combescure, F. Hild, and S. Roux. Three dimensional experimental and numerical multiscale analysis of a fatigue crack. Comp. Meth. Appl. Mech. Eng., 199:1307-1325, 2010.

[47] P. Reischig, L. Helfen, A. Wallert, T. Baumbach, and J. Dik. High-resolution non-invasive 3D imaging of paint microstructure by synchrotron-based X-ray laminography. Apply. Phys. A, 111:983-995, 2013.

[48] S. Ren, T.F Morgeneyer, S. Forest, M. Maziere, and G. Rousselier. Portevin-le chatelier effect triggered by complex loading paths in 2139 t3 aluminium alloy. Submitted for publication, 2017.

[49] J.R. Rice. The localization of plastic deformations. In W.T. Koiter, editor, Theoretical and Applied Mechanics, pages 207-220. North-Holland, 1976. 
[50] Gilles Rousselier, Thilo F. Morgeneyer, Sicong Ren, Matthieu Mazière, and Samuel Forest. Interaction of the Portevin-le Chatelier phenomenon with ductile fracture of a thin aluminum $\mathrm{CT}$ specimen: experiments and simulations. International Journal of Fracture, 206(1):95-122, 2017.

[51] S. Roux, F. Hild, P. Viot, and D. Bernard. Three dimensional image correlation from X-Ray computed tomography of solid foam. Comp. Part A, 39(8):1253-1265, 2008.

[52] D. Steglich and T. F. Morgeneyer. Failure of magnesium sheets under monotonic loading: 3D examination of fracture mode and mechanisms. Int. J. Fract., 181:105-112, 2013.

[53] T. Taillandier-Thomas, S. Roux, T.F. Morgeneyer, and F. Hild. Localized strain field measurement on laminography data with mechanical regularization. Nucl. Inst. Meth. Phys. Res. B, (324):70-79, 2014.

[54] V. Taupin, J. Chevy, and C. Fressengeas. Effects of grain-to-grain interactions on shear strain localization in al-cu-li alloys. Int. J. Sol. Struct., 99:71-81, 2016.

[55] Z. Tomicevic, F. Hild, and S. Roux. Mechanics-aided digital image correlation. J. Strain Analysis, 48:330-343, 2013.

[56] T. Ueda, L. Helfen, and T.F. Morgeneyer. In situ laminography study of three-dimensional individual void shape evolution at crack initiation and 
comparison with Gurson-Tvergaard-Needleman-type simulations. Acta Mat., 78:254-270, 2014.

[57] F. Xu, L. Helfen, T. Baumbach, and H. Suhonen. Comparison of image quality in computed laminography and tomography. Opt. Express, 20:794-806, 2012.

[58] L. Xue, J. Faleskog, and J.W. Hutchinson. Tension - torsion fracture experiments - Part II: Simulations with the extended Gurson model and a ductile fracture criterion based on plastic strain. Int. J. Solids Struct., 50(25-26):4258 - 4269, 2013.

[59] U. Zerbst, M. Heinimann, C. Dalle Donne, and D. Steglich. Fracture and damage mechanics modelling of thin-walled structures. an overview. Eng. Fract. Mech., 76:5-43, 2009. 


\section{Appendix A: Additional Results}

\section{Additional damage quantification}

A similar analysis to that in Section 3.2 is repeated, this time by following void nucleation and growth in two extracted subsets inside ROI 1 (i.e., ES1 and ES2, Figure 17(a)). ES1 is located inside the zone where two strained bands crossed each other and that were active during the whole loading history. ES2 occupied a zone with significantly lower strain activity. Although the present method intrinsically incorporated several imperfections (e.g., the analysis does not always exactly follow the same portion of the material and does not account for overall grey level variations), still the ability to record stable void growth was preserved as demonstrated in Figure 17(b). Only after loading step (0)-(6) did the porosity increase inside the strained band. The void growth ratio inside and outside the bands did not differ significantly, yet the final crack path followed the band position.
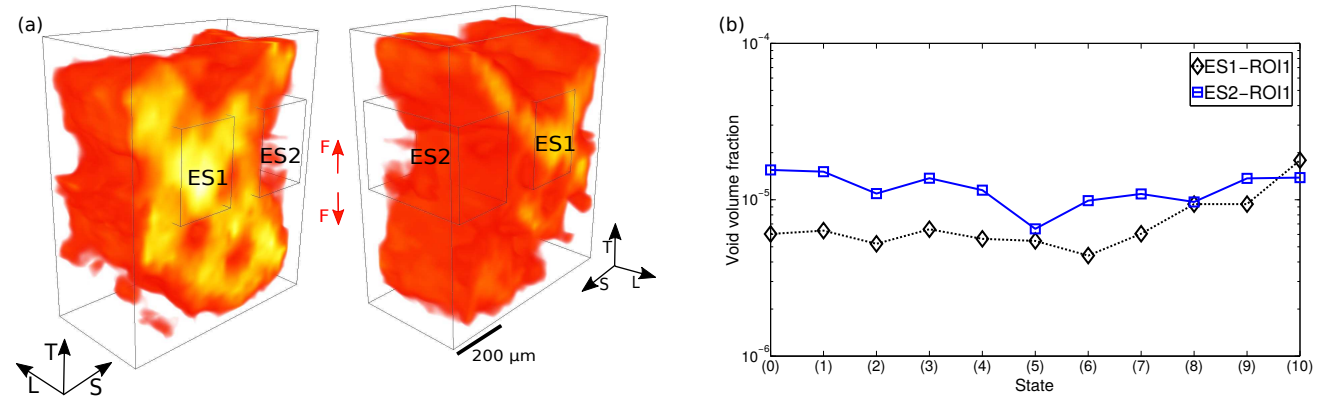

Figure 17: (a) Positions of the subsets depicted on the thresholded von Mises effective strain field. (b) Void growth over the loading history inside two subsets of ROI 1 
An additional damage characterization is carried out by observing the final grey level residual $\rho(\boldsymbol{x})$ of DVC analyses (Subsection 2.3). Not only does it serve for quality inspection, but it also provides useful information for detecting damage occurring for which the grey level conservation (see Equation (2)) would be violated. It should be recalled that the corrected volumes were updated at each iteration on a sub-voxel scale by using grey level interpolation (in this work a trilinear interpolation scheme was employed). This means that by using residual fields sub-voxel resolutions can be improved in the grey level registration procedure.

In their original form, the residual fields have been evaluated voxel-wise (see Equation (3)). A first insight can be obtained by observing standard deviation values of the residuals inside ROI 1 . They were virtually the same for all calculations and very close to the levels observed for the resolution analysis. These results are shown in Figure 18 where all the values have been normalized by the dynamic range of the reference volume (i.e., 256 gray levels). The fact that there is a small drift for direct calculations is probably due to the complexity of the kinematic fields, which cannot be fully captured with the chosen discretization. 


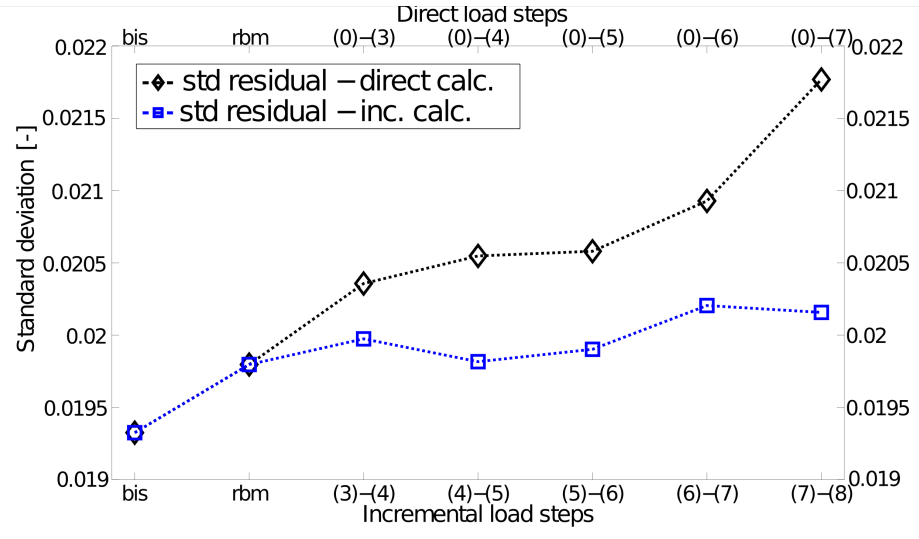

Figure 18: Standard deviation of the residual fields for incremental and direct calculations

For a deeper understanding, a field characterization is required. Figure 19 shows the residual distribution on section B-B (Figure 2(b)) and that normal to it (mid-thickness ROI section) for the last direct (i.e., (0)-(7)) and last incremental (i.e., (7)-(8)) DVC registrations. There were no significant features (zones) with high residuals confirming the values reported in Figure 18. This result indicates grey level conservation (i.e., no new voids nucleate, nor void growth) and continuity of the displacement field, hence no significant damage growth occurred. Therefore the cumulation of strains in the ROI was mostly due to the strained band activity (as shown above) and did not induce significant residual deviations. 


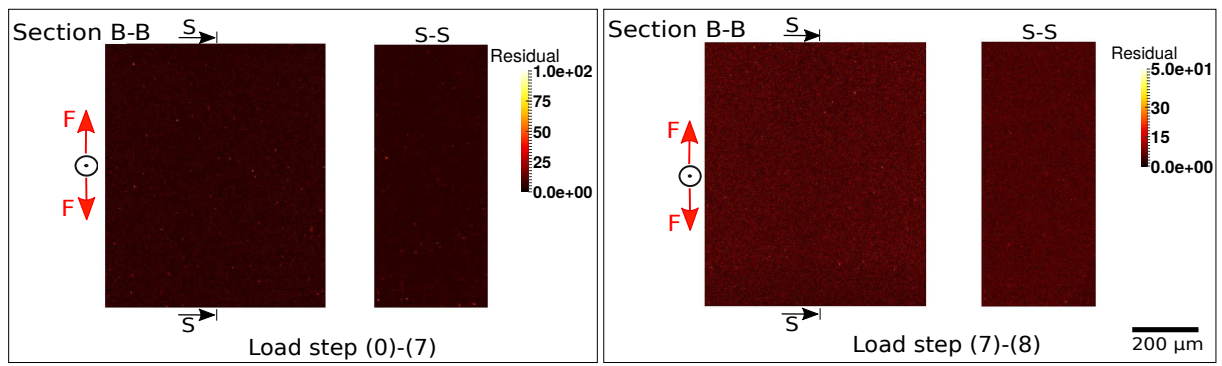

Figure 19: Grey level residual distribution over section B-B (Figure 6(b)) and the section normal to it (S-S) for the last converged direct (left) and incremental (right) calculations

\section{Surface DIC results}

Since 2D images of the specimen surface were also acquired during the experiment (Figure 20) T3-DIC analyses were performed [55]. The ROI position of DIC analyses is depicted in Figure 20(a) whilst the results in terms of normal strains in the loading direction $\epsilon_{T T}$ are reported in Figure 20(c). The final crack started to propagate at State (11) in a"roof-top" manner resulting in short surface cracks. These two separate cracks appear in 2D images (see yellow arrows) as well as in grey level residual fields of the last DIC calculation (Figure 20(b)). The part of the upper crack closer to the notch root is that where the mentioned mismatch between the early strained bands and the final crack position was found. However, from the DIC results it can be seen that the strained horizontal band matching the position of upper crack started to activate after loading step (0)-(7) whilst the final crack appeared at State (11). Such a shift of deformation activity to the upper horizontal band confirms the activation of the band orthogonal to 
those shown in Figure 12 (ROI 2) later in the loading history. It is the left part (close to the DVC ROI surface) of effective strain fields in Figure 12 $(L=460 \mu \mathrm{m})$ that corresponds to the DIC results.

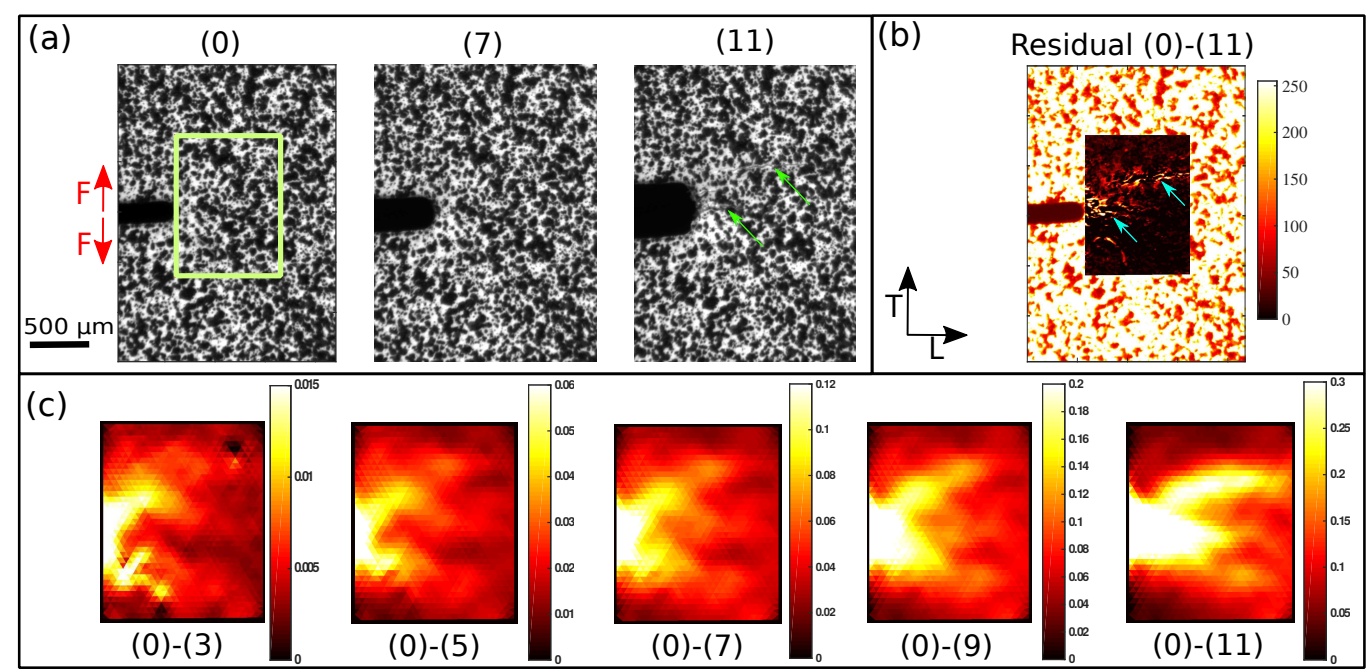

Figure 20: (a) 2D images of the CT like specimen surface during loading. (b) Grey level residual field from the last direct DIC calculation (between undeformed State (0) and State (11)). (c) Normal strains in the loading direction $\epsilon_{T T}$ for direct DIC calculations 